\title{
Music as a coevolved system for social bonding
}

Article

Accepted Version

Savage, P. E., Loui, P., Tarr, B., Schachner, A., Glowacki, L., Mithen, S. and Fitch, W. T. (2021) Music as a coevolved system for social bonding. Behavioral and Brain Sciences, 44. pp. 1-22. ISSN 1469-1825 doi:

https://doi.org/10.1017/S0140525X20000333 Available at https://centaur.reading.ac.uk/95527/

It is advisable to refer to the publisher's version if you intend to cite from the work. See Guidance on citing.

To link to this article DOI: http://dx.doi.org/10.1017/S0140525X20000333

Publisher: Cambridge University Press

All outputs in CentAUR are protected by Intellectual Property Rights law, including copyright law. Copyright and IPR is retained by the creators or other copyright holders. Terms and conditions for use of this material are defined in the End User Agreement.

\section{www.reading.ac.uk/centaur}

\section{CentAUR}

Central Archive at the University of Reading 
Reading's research outputs online 


\title{
Behavioral and Brain Sciences (forthcoming)
}

\section{This Target Article has been accepted for publication and has not yet been copyedited and proofread. The article may be cited using its doi (About doi), but it must be made clear that it is not the final version.}

\section{Music as a coevolved system for social bonding}

Authors:

Patrick E. Savage

Faculty of Environment and Information Studies, Keio University, Fujisawa 252-0882, Japan

psavage@sfc.keio.ac.jp $\quad \underline{\text { http://PatrickESavage.com }}$

Psyche Loui

College of Arts, Media and Design, Northeastern University, Boston, MA 02115

p.loui@northeastern.edu http://www.psycheloui.com

\section{Bronwyn Tarr}

Institute of Cognitive and Evolutionary Anthropology \& Department of Experimental Psychology, University of Oxford, Oxford, OX2 $6 P N, U K$

bronwyn.tarr@anthro.ox.ac.uk; bronwyntarr01@gmail.com https://www.anthro.ox.ac.uk/people/dr-bronwyn-tarr

\section{Adena Schachner}

Department of Psychology, University of California San Diego, La Jolla, CA 92093

schachner@ucsd.edu https://madlab.ucsd.edu

Luke Glowacki

Department of Anthropology, Pennsylvania State University, University Park, PA 16802

glowacki@psu.edu https://www.hsb-lab.org/

\section{Steven Mithen}

Department of Archaeology, University of Reading, Reading RG6 6AB, UK

s.j.mithen@reading.ac.uk $\underline{\text { http://www.reading.ac.uk/archaeology/about/staff/s-j-mithen.aspx }}$

\author{
W. Tecumseh Fitch \\ Department of Cognitive Biology, University of Vienna, Vienna 1090, Austria \\ tecumseh.fitch@univie.ac.at https://homepage.univie.ac.at/tecumseh.fitch/
}

\section{Word counts:}

Abstract: 229

Main text: 13,659

References: 8,387

Entire text- total + addresses etc.: 22,806

\section{Abstract:}

Why do humans make music? Theories of the evolution of musicality have focused mainly on the value of music for specific adaptive contexts such as mate selection, parental care, coalition signaling, and group cohesion. Synthesizing and extending previous proposals, we argue that social bonding is an overarching function that unifies all of these theories, and that musicality enabled social bonding at larger scales than grooming and other bonding mechanisms available in ancestral primate societies. We combine cross-disciplinary evidence from archaeology, anthropology, biology, musicology, psychology, and neuroscience into a unified framework that accounts for the biological and cultural evolution of music. We argue that the evolution of musicality involves gene-culture coevolution, through which proto-musical behaviors that initially arose and spread as cultural inventions had feedback effects on biological evolution due to their impact on social bonding. We emphasize the deep links between production, perception, prediction, and social reward arising from repetition, synchronization, and harmonization of rhythms and pitches, and summarize empirical evidence for these links at the levels of brain networks, physiological mechanisms, and behaviors across cultures and across species. Finally, we address potential criticisms and make testable predictions for future research, including neurobiological bases of musicality and 
relationships between human music, language, animal song, and other domains. The music and social bonding (MSB) hypothesis provides the most comprehensive theory to date of the biological and cultural evolution of music.

\section{Keywords:}

comparative; cooperation; cultural evolution; harmony; language; music; prediction; reward; synchrony; vocal learning

\section{Introduction}

Darwin famously considered music to be a puzzle for evolutionary theory. Music is universal across human cultures (Brown \& Jordania 2013; Mehr et al. 2019; Savage et al. 2015), yet its function seems mysterious, since "neither the enjoyment nor the capacity of producing musical notes are faculties of the least use to man in reference to his daily habits of life..." (Darwin 1871, p. 33). Darwin went on to speculate that music first evolved "for the sake of charming the opposite sex", after which language "derived from previously developed musical powers".

Since Darwin there has been no shortage of hypotheses about why and how music evolved (cf. Honing et al. 2015; Wallin et al. 2000). The null hypothesis is that music is an evolutionarily "useless" by-product of other evolved capacities, with no adaptive function and involving no direct selection for musical capacities (Pinker 1997, p. 528). Others hypothesize that musicality evolved for specific adaptive purposes, including signaling mate quality (Miller 2000), advertising male coalitions (Hagen \& Bryant 2003; Merker 2000), or soothing infants (Dissanayake 2000; Falk 2004; Mehr \& Krasnow 2017). Many authors have discussed the evolutionary value of music in facilitating group cohesion (e.g., Benzon 2001; Brown 2000a, 2007; Cross \& Morley 2009; Dissanayake 2009; Dunbar 2012a; Freeman 2000; Gioia 2019; Huron 2001; Loersch \& Arbuckle 2013; McNeill 1995; Merker et al. 2018; Mithen 2005; Oesch 2019; Patel 2018; Roederer 1984; Schulkin \& Raglan 2014; Trainor 2018; Trehub et al. 2018), sometimes suggesting that music may have arisen via group selection (especially Brown 2000a). Although such proposals succeed in explaining some properties (or genres) of music, we argue that no single account succeeds as a general explanatory framework for the evolution of human musicality. Our purpose in the present target article is to synthesize and extend previous proposals into a new, parsimonious framework that can explain and predict many aspects of human music-making.

Our argument is that human musicality is a coevolved system for social bonding. Crucially, following Honing (2018) and others, we clearly distinguish between music and musicality. "Music" encompasses the diverse cultural products generated by and for music making: songs, instruments, dance styles, etc. In contrast, "musicality" encompasses the underlying biological capacities that allow us to perceive and produce music. Distinguishing these clearly is crucial because musical systems are diverse, culture-specific products of cultural development, while musicality comprises multiple biological mechanisms, shared across human cultures, that enable musical production, perception and enjoyment ${ }^{1}$. Musicality is not a monolithic trait evolved to solve one particular problem (coalition signaling, infant mood regulation, sexual attraction, etc.), but rather a set of capabilities that can be utilized in different ways to support multiple functions, all involving social affiliation, but no one of which is the "primary" or "original" function.

The key phrase "social bonding" refers to the formation, strengthening and maintenance of affiliative connections ("bonds") with certain conspecifics (i.e., the set of social processes that engender the bonded relationships that underpin prosocial behaviour). As a group-living primate species, such bonds are psychologically and biologically central to human survival and reproduction (e.g. via enhanced predator protection, cooperative child-rearing, collaborative foraging, expansion and defense of territories; Hrdy 2009, Dunbar \& Schultz 2010, Dunbar 2012b, Tomasello \& Vaish 2013). For the purpose of this paper we use "social bonding" as an umbrella term to encompass both bonding processes (over short and longer time scales) and their effects. Consequently, we take "social bonding" to encompass a variety of social phenomena including social preferences, coalition formation, identity fusion, situational prosociality, and other phenomena that bring individuals together. The social functions of music share a general social utility: to forge and reinforce affiliative inter-individual relationships, for example by synchronizing and harmonizing the moods, emotions, actions or perspectives of two or more individuals. Crucially, we argue that music achieves this in a variety of situations where language is less effective, and on a scale greater than that achievable by the ancestral bonding mechanisms available to other primates (e.g., grooming). We argue that social bonding promotes, and is the consequence of, interactions not only during music making, but also subsequently via long-lasting changes in affiliative dispositions of group members towards one another, and their

\footnotetext{
${ }^{1}$ For discussion of practical and ethical challenges involved in defining and comparing "music" and "musicality" in cross-culturally valid ways, see Nettl (2015); Savage (2019b); Jacoby, Margulis, et al. (2020); Ewell (2020); Danielle Brown (2020); and Iyer \& Born (2020).
} 
associated longer-term prosociality. Because social interactions involve multiple levels of group structure, our conception of social bonding also includes darker phenomena such as out-group exclusion that bring certain individuals closer together by pushing away others (see Section 6.4).

The final keyword here is "coevolved": we argue that culturally evolving systems of music (Savage 2019a) have developed in tandem with the human capacity for musicality through a process of gene-culture coevolution. We build on recent arguments by Patel (2018) and Podlipniak (2017), who suggest that music arose initially as a cultural "invention" that created the context for later selection enhancing human musicality. In much the same way that the use of fire by early hominins provided the preconditions for biological adaptations to cooked food (Wrangham 2009), or the invention of dairy farming in some European and African cultures created selection for lactase persistence (Tishkoff et al. 2007), early instantiations of music provided the selective preconditions for later neurobiological changes underlying human musicality. Notably, both Patel and Podlipniak identified social bonding as a candidate function driving such gene-culture coevolution, with Patel (2018, p. 118) noting the possibility that "musical behavior first arose as a human invention and then had (unanticipated) beneficial effects on social cohesion." We argue that because music had multiple adaptive effects on social bonding, this led to subsequent selection (both genetic and cultural) for the ability and motivation to make particular forms of music -- music that has features that most effectively function to promote social bonding. This combination of cultural and biological selection led to the particular features and ubiquity of modern human music and musicality.

Our article closely examines this claim, and provides a framework for understanding the biological and cultural evolution of music, taking this argument as foundational. We provide a detailed cross-disciplinary review of the evidence for specific mechanisms by which music functions to enhance social bonding, and consider how some of the mechanisms underlying musicality may have coevolved with music. Like Patel, we take for granted the large and sophisticated literature on gene-culture coevolution in general, and will not review it here (cf. Cavalli-Sforza \& Feldman 1981; Boyd \& Richerson 1985; Durham 1991; Jablonka \& Lamb 2005; Laland et al. 2000, 2010; Richerson et al. 2010; Henrich 2016; Tomlinson 2018). However, we do not see the "invention" of music as a unitary event later followed by genetic adaptation, but rather as an iterated process where different proto-musical components of musicality arose over an extended period as behavioral innovations that, due to initial positive effects, generated new cognitive and social niches for subsequent biological adaptations, themselves yielding new innovations, etc. in a virtuous spiral. We thus posit essentially an iterated Baldwin effect (Baldwin 1896; Bateson 2004; Griffiths 2003; Podlipniak 2017), or more generally, prolonged cognitive "niche construction" (Laland et al. 2000). This mechanism is closely related to many contemporary models of language evolution involving a series of "protolanguages" (Arbib 2005; Fitch 2010, 2017). Although hypotheses about the specific ordering of events involved (e.g., Mithen 2005, Dunbar 2012a) are useful, it is not our purpose here to propose a specific sequence, but rather to advance a new conception of the entire process.

Mehr, Krasnow, Bryant and Hagen (in this issue) present a contrasting hypothesis for the origins of music. Their hypothesis synthesizes and extends their previous proposals (Hagen \& Brant 2003; Mehr \& Krasnow 2017) into a generalized "credible signaling" hypothesis that incorporates signaling of both coalition strength and parental attention. They also present critiques of the social bonding hypothesis and other candidate hypotheses. The BBS editors decided that publishing these two target articles with contrasting hypotheses would stimulate productive commentary beyond that usually possible for only a single target article. Both target articles originated from the same symposium on "The Origins of Music in Human Society", , but differ in multiple ways in addition to the focus on social bonding vs. credible signaling. In particular, Mehr et al. take an approach grounded in evolutionary psychology, focused on demonstrating domain-specificity and evidence for adaptation. In contrast, our approach emphasizes cultural evolutionary theory, including in particular gene-culture coevolution and cognitive niche construction (cf. Laland \& Brown 2011). We take a pluralistic approach to adaptation and modularity, involve experts from diverse disciplines to synthesize evidence into a single framework, and propose testable predictions for future research. We expand on more detailed contrasts between the two articles in Section 6 .

The following sections lay out the details and implications of the music and social bonding (MSB) hypothesis. Section 2 describes the proposed evolutionary functions and coevolutionary process. Section 3 details cross-disciplinary evidence supporting the MSB hypothesis. Section 4 specifies the neurobiological mechanisms proposed to underlie music's social bonding functions. Section 5 describes testable predictions that follow from the MSB hypothesis. Section 6 addresses a number of potential criticisms of our hypothesis, and Section 7 provides a brief conclusion.

\footnotetext{
${ }^{2}$ The symposium program is available at https://www.iast.fr/sites/default/files/IAST/conf/royaumont/royaumont_program051217.pdf
} 


\section{Social bonding as a unifying function in the evolution of musicality}

The Music and Social Bonding (MSB) hypothesis posits that core biological components of human musicality evolved as mechanisms supporting social bonding. Musicality relies on multiple neurocognitive components, which likely evolved at different times and for different reasons: musicality is more a cognitive toolkit than a single tool (Fitch 2015a). Most of the tools in this musical toolkit function to facilitate social bonding, but some may also be used for non-social purposes such as individual mood regulation (see Section 6.5).

We avoid arguing for one specific single adaptive function for music (e.g. coalition advertisement, courtship, or infant mood regulation) because we think it unlikely that a single "main" evolutionary function for complex, multi-component abilities like language or music exists. Imagine asking the parallel question "what is vision for?" and coming up with a hypothesis set including "spotting predators", "judging mate quality", "finding food", and "avoiding obstacles". It seems clear that these are all functions of vision, and all provide potential causal explanations for adaptive improvements in vision during evolution. But the desire to identify ONE function as primary seems misguided. A better approach is mechanistic: we ask "what are lenses for?," and answer in engineering terms: lenses are for focusing an image on the retina, to enable accurate visual perception. Whether the image is of a predator, mate, or food is not critical, since improved visual resolution will aid them all.

Turning to music, "social bonding" provides an umbrella explanation analogous to "vision is for seeing". Particular design features of music (singing discrete pitches, generating an isochronous beat, use of repetitive patterns based on small-integer ratios) function mechanistically to enhance predictability, aiding synchronization and harmonization when multiple people sing, dance, and play instruments together. Coherent and harmonious merging of sounds and movements during group activity leads to positive feelings of prediction, fulfillment of expectation, and mutual accomplishment. These, through activation of the dopaminergic reward system and other pathways, have affiliative emotional and rewarding effects immediately and also long after music-making ceases (see Section 4). Crucially, the resulting strengthened social bonds are operative over multiple types and sizes of groups, ranging from dyads (e.g., parent and infant, potential mates) to bands of small coalitions and large groups of unrelated individuals (Fig. 1). Social bonding through music thus produces its ultimate evolutionary dividends in multiple complementary ways, including a larger group of potential allies, increased child rearing success, increased mating success, and better-functioning coalitions.

\begin{tabular}{|c|c|c|}
\hline \multicolumn{3}{|c|}{ Music as a co-evolved system for social bonding } \\
\hline Infant Care & Mate Bonding & Group Cohesion \\
\hline Dyads & & $\begin{array}{l}\text { Large groups of unrelated } \\
\text { individuals }\end{array}$ \\
\hline $\begin{array}{l}\text { Increased } \\
\text { parenting success }\end{array}$ & $\begin{array}{l}\text { Increased } \\
\text { mating success }\end{array}$ & $\begin{array}{l}\text { Larger group of potential } \\
\text { allies, better functioning } \\
\text { coalitions }\end{array}$ \\
\hline \multicolumn{3}{|c|}{$\begin{array}{l}\text { Music forges and reinforces affiliative inter-individual relationships by } \\
\text { synchronizing and harmonizing the moods, emotions, actions or } \\
\text { perspectives of two or more individuals }\end{array}$} \\
\hline
\end{tabular}

Figure 1. We propose that supposedly competing hypotheses for the evolution of human music, including mate bonding, parent-infant bonding, and group cohesion (within both small coalitions and larger groups), are complementary subcomponents of a broader social bonding function. 


\subsection{Ancestral bonding mechanisms}

Why was social bonding adaptive for our ancestors, and in what ways does music improve or increase social bonding? Group living comes with costs (e.g., increased local competition for food and mates) and benefits (e.g., safety in numbers, cooperative hunting/defense). Animals that live in groups, particularly primates, have evolved mechanisms that help balance these costs and benefits by forging strong affiliative bonds: good quality, persistent, differentiated inter-individual commitments that require investment of time and energy (Dunbar 1991). Strong social bonds enhance individuals' prospects of receiving support through coalitions, which, in certain primate species, influence dominance rank and reproductive performance (Silk 2007). These coalitions form the backbone of successful cooperative hunting, child rearing, and joint defense against predators or competitors (Dunbar $\&$ Shultz 2010). Ecological factors typically constrain the size of a group, but larger groups of well-coordinated, strongly bonded humans enabled exploitation of new forms of resources (e.g., larger prey), and more reliable protection from predators (Dunbar 2012b).

Ancestral bonding mechanisms (ABMs) in other primates include grooming, play, and - in some species - non-procreational sex. These ABMs are essentially dyadic (or for play, very small groups mostly limited to young animals), and require substantial time commitments even in small groups if all individuals in the group are to invest in all others. Although vocal duets are present in tropical birds and some primates (Farabaugh 1982; Haimoff 1986; Mann et al. 2009; Thorpe 1972), group vocal choruses that are both differentiated and coordinated appear nearly unique to humans (but see Mann et al. 2006 for the fascinating example of the groupchorusing plain-tailed wren).

As Dunbar (1993) has argued, the steady increases in group size, complexity, and fluidity that occurred during hominin evolution put increasing strain on ABM-based social bonds. Beyond group sizes of 20 or so, dyadic bonding based on ABMs like grooming became unsustainably time-consuming, so supra-dyadic bonding mechanisms were needed. Dunbar (2012a) suggests that another ABM in great apes and humans was laughter (Davila-Ross et al. 2009), which facilitates social bonds among reasonably large groups. However, there are limits to a bonding mechanism based on laughter: Unlike music, which people can intentionally choose to engage in at any time, large group laughter can be difficult to elicit and to sustain for long periods. Music may have provided our ancestors with a novel system that, like laughter, allowed for simultaneous bonding with a larger group of individuals, but across a broader set of times and contexts, and for longer periods of time than otherwise possible (Dunbar 2012a; Launay et al. 2016). This new system augmented the smaller-scale ABMs that became less robust in larger groups. Specific design features of human musicality particularly our capacity and proclivity to produce repetitive, synchronized, harmonized music for extended periods - provided a flexible toolkit for bonding, allowing our ancestors to achieve social bonding on a large scale.

\subsection{Design features of musicality}

\subsubsection{Rhythm and dance}

Most music has two distinctive rhythmic components: an isochronous (equal-timed) beat, and a metric structure (a hierarchical arrangement of sonic events into small groups with differentially accented constituents; Arom 1991; London 2004; Savage et al. 2015). These features together provide a predictable, repetitive structure underlying extended, coordinated and varied group performances, while allowing room for variation and improvisation. Isochronicity and metric structure make the performance predictable, which facilitates planning synchronized and coordinated movements (e.g., dancing). While synchronization solely to the beat (e.g. in marching or unison chanting) allows large groups to integrate, it tends to submerge individual contributions. Meter solves this problem by allowing many individuals to contribute, out of phase, to the same integrated rhythm. Neither of these core design features of musicality appears well-designed for solo performances, but they support the synchronized and coordinated musical sounds and dance movements of groups that are widespread features of human musical systems (Savage et al. 2015).

Dancing is another intrinsically rhythmic component of human musicality (cf. Fitch 2015a/b; Laland et al. 2016). Even newborn infants perceive a musical beat (Winkler et al. 2009), and dance develops early: infants hearing music produce spontaneous rhythmic movements during their first year, although the ability to entrain these movements reliably to a beat takes several years to develop (Kim \& Schachner, 2020; McAuley et al. 2006; Merker et al. 2009; Zentner \& Eerola 2010). The capacity to perceive and move to a beat is a core component of musicality, rare among vertebrates (Patel 2014; Schachner et al. 2009) but universal across human cultures (Donald Brown 1991). Dance provides an energetic mode of musical participation that is accessible to large numbers of individuals 
regardless of age, familiarity with the music, or instrumental/singing virtuosity. In addition to its visual effects, dance can also generate an auditory signal, e.g. due to foot stamping or hand clapping, and certain styles of dance (such as tap dancing) create their own sonic accompaniment. These factors suggest that dance is a core part of music-making ("musicking") and not a separate domain (Tarr 2017).

Dance thus expands the potential circle of rhythmically coordinated participants in musical interactions. The inclusive aspect of human musicality provided by dance is predicted by the MSB hypothesis, but poses a challenge to hypotheses seeing music primarily as a signal of virtuosity. Hereafter, we consider dance a core component of musical performance.

\subsubsection{Melody, harmony, and vocal learning}

The human capacity for song entails vocal production learning: the ability to imitate and learn vocal patterns beyond our speciestypical repertoire of screams, laughter, etc. By about 2 or 3 years of age (often earlier), children reproduce songs that their caregivers sing to them, with intact pitch range and contours (Trehub 2016). Young children commonly exhibit greater fluency in song than in speech (e.g., singing Twinkle Twinkle Little Star from beginning to end with fractured, word-like sounds). This vocal learning ability is highly developed in humans relative to other primates, and the neurobiological mechanisms of its evolution are relatively wellunderstood, due in part to its convergent evolution in songbirds and other non-human species (Janik \& Slater 1999, Jarvis 2019; Fitch 2015a; Syal \& Finlay 2011; see Section 4.4 for details). Vocal learning forms a foundation for group participation in singing culturespecific songs.

In contrast to the continuously varying pitch of normal speech, the discrete pitches used in song and instrumental music generate predictable sequences that enable frequency matching between individuals during group music production (Merker 2002; Savage et al. 2015). Unison performance in which multiple parts produce the same melodies at either the same frequencies (1:1 frequency ratio) or an octave apart (2:1 ratio) is so widespread among humans it is often not even considered a form of harmonization (although cf. Jacoby et al. 2019 for evidence that octave equivalence is not completely universal). Octave singing in particular represents the most universal form of musical harmony: different pitches performed simultaneously with maximally overlapping acoustic spectra (cf. Bowling \& Purves 2015). The common tendency for men and women to sing together in octaves is paralleled by the roughly octave difference in men and women's average vocal pitch, based on vocal anatomy (Titze 1989). This is an unusual feature among primates (and mammals more generally) not observed in chimpanzees (Grawunder et al. 2018) - a potential anatomical adaptation for vocal harmonization.

Harmonious overlapping of acoustic spectra also shapes another common design feature: Musical systems around the world restrict pitches to scales containing a limited number of discrete pitch classes (rarely more than 7; Savage et al. 2015). These pitch classes often reflect small-integer frequency relationships which sound consonant together (e.g., the 3:2 frequency ratio underlying musical fifths, 4:3 ratios for fourths, etc.; Bowling et al. 2018; Gill \& Purves 2009; Kuroyanagi et al. 2019; McDermott et al. 2010; Terhardt, 1984). By producing pitches that adhere to scales, groups of singing individuals effectively minimize uncertainty in fundamental frequency, thus maximizing harmony via spectral alignment (Sethares 2004). Coordinating with other individuals musically, by aligning acoustic spectra, can sound pleasing and promote bonding. The specific mechanisms and causal relationships behind this effect remain contested (Bowling \& Purves 2015; Bowling et al. 2017, 2018; Harrison \& Pearce 2019; Jacoby et al. 2019 ; Large et al. 2016; McBride \& Tlusty 2020; McDermott et al. 2010, 2016; Merker et al. 2018; Pfordresher \& Brown 2017). Regardless, scales facilitate harmony, where individual voices/instruments combine consonantly - another design feature supporting group coordination but not solo performance.

\subsubsection{Repetitive structure}

The synchronization of rhythms and harmonization of pitches described above is facilitated and enhanced by the widespread use of repetitive musical structures (Savage et al. 2015). Structural building blocks can range from short rhythmic and/or melodic motives of only a few notes, to entire phrases, to large-scale sections or entire works. The level of repetition in music is one of its most striking differences from language (Fitch 2006; Margulis 2014), and multiple repetitions of a recording of a spoken phrase cause it to sound sung rather than spoken (Deutsch et al. 2011). Repetition enhances memorization and predictability, allowing multiple performers to engage in long periods of coordinated music-making, with all-night music-and-dance rituals common from contemporary Western nightclub culture to ethnographic descriptions of small-scale societies (Merriam 1964; Thornton 1995). In contrast, language and ancestral bonding mechanisms such as laughter are more difficult to sustain for long periods, making them less suitable for the kind of sustained inclusive interactions that promote the strongest social bonds. However, extreme repetition can lead to boredom and to a 
dearth of memorable distinguishing features, preventing music from serving as a cue of social identity (see below). Both human and bird songs tend to balance repetition and novelty in the form of repetition with variation (Kroodsma 1978; Lomax 1968).

\subsubsection{Music and social identity}

A final potential design feature of culturally-transmitted group music concerns its role in flexibly and hierarchically indicating kinship and group identity (Stokes 1994; Turino 2008). Because songs are variable, complex and memorable, two people knowing the same song likely acquired this knowledge via social learning -- and thus are likely to share a common socio-cultural history. Thus, shared knowledge of musical repertoire provides information about shared socio-cultural background (Soley \& Spelke 2016; Schachner et al. 2018). Musicality may have coevolved in support of this social bonding function: Cultural innovations created a wide variety of musical styles and features, and musical knowledge became a cue to social history and cultural group membership. This created selective feedback favoring individuals who tended to perceive music as a cue to group membership, as they would have more accurate ideas about others' social group membership. This hypothesized combination of cultural and biological evolution would lead to an evolved bias to use music as a cue to guide and facilitate social interactions, consistent with findings that shared musical knowledge serves as a social cue from early in childhood through adulthood (see Sections $3.3 \& 3.4$ ).

Synchronized and harmonized group performances help cement group identity, and eventually allow skilled participation in ritualized performances to serve as a hard-to-fake indicator of group membership. Furthermore, the existence of diverse pieces and sub-styles allows subgroups to express their uniqueness within a broader shared musical repertoire or style. Such expressions of identity at multiple hierarchical levels are useful because human biological and cultural evolution has been characterized by increasing complexity of social structure, as exemplified by the large-scale nation-states characteristic of modern human societies (Turchin et al. 2018). Thus, group musical performance - including dance - facilitates lasting, culturally evolving indicators of group identity and bonds - akin to passwords or shibboleths (cf. Feekes 1982, Fitch 2004) - that extend beyond individual recognition and memory, aiding intercultural marriage and trade.

\subsection{Gene-culture coevolution}

These specific design features and their interactions - dancing to an isochronous beat with a metrical hierarchy, singing learned melodies based on discrete scales in harmony, using predictable, repetitive musical structures, and using musical performances as cues for social identity - are widespread throughout the world's musical systems (Savage et al. 2015; see Section 3.1). These features have clear functions for group performance, but little or no function in solo performance (hence their rarity in birdsong, whale song, and certain solo human music genres such as lament; Tolbert 1990, Frigyesi 1993). These design features are therefore predicted a priori by the MSB hypothesis, but not by solo signaling hypotheses such as sexual selection for mate attraction (Miller 2000) or maternal singing to infants (Mehr \& Krasnow 2017; Mehr et al. This issue). While these features promote coordination in dyadic music (e.g., duets) and memorability/communicative power in solo music (e.g., lullabies; Corbeil et al. 2016; Cirelli \& Trehub 2020), their added value in supporting extended, coordinated group performances is most evident for larger groups.

MSB posits an extended timeline in which different core mechanisms of musicality arose through a coevolutionary "virtuous spiral." While many of the specific design features above could in principle function independent of the others, and would prove adaptive independently at any proto-musical stage, over evolutionary time we hypothesize that isochronous beats coevolutionarily enabled meter and dance, and that pitched singing enabled scale-based melody and harmony. Each new feature added value in supporting extended, coordinated, harmonious group performance. Each feature may have been initially based on behavioral innovations involving synchronization of the ancestrally individualistic displays seen in other great apes (e.g. chimpanzee pant-hoot displays and fruit tree "carnival" displays, cf. Merker 1999; Merker et al. 2018). However, each innovation opened a new cognitive/musical niche selecting for independent specialization of relevant neural circuitry (see Section 4).

Early instantiations of music provided selective preconditions for later cognitive and neurobiological changes underlying human musicality, analogous to the well-documented examples of gene-culture coevolution involving fire and dairy farming. Cultural innovations created a variety of proto-musical behaviors, with musical knowledge becoming a potential cue to social history and cultural (sub-)group membership. For example, this could have created selective feedback favoring individuals who used music as cues to group membership. Together, biological and cultural coevolution created a framework for the coordinated, harmonious, emotional group performances that are evident today throughout the world's musical cultures. The major inter-relationships among 
these components of human musicality are summarized in Figure 2 (but see Section 6.3 for caveats regarding causality in our proposed coevolutionary mechanisms).

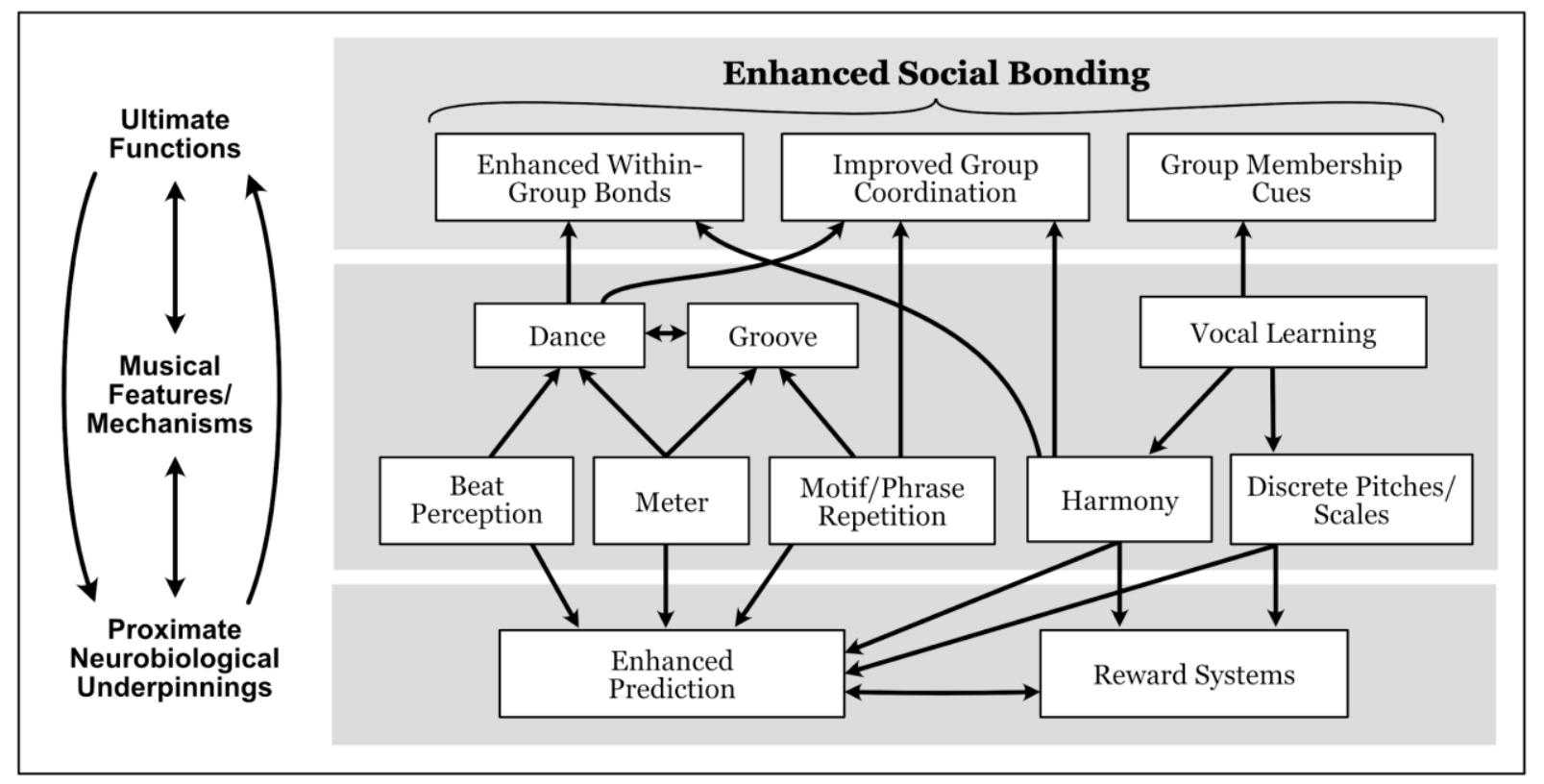

Figure 2. Proposed coevolutionary relationships among multiple musical features and mechanisms, indicating their contributions to ultimate functions by facilitating social bonding in multiple ways, their proximate neurobiological underpinnings in prediction and reward systems, and feedback loops among these different levels.

\subsection{Benefits of social bonding}

We hypothesize that musicality increased the number of "simple" relationships (e.g. "friends"), and increased the quality (depth and complexity) of existing relationships. The opportunity for many individuals to participate productively in social interaction through proto-musical behaviors facilitates an efficient bonding mechanism for groups of varying sizes, thereby conferring associated benefits (as outlined in Section 2.1). However, we must consider the nature of the subsidiary relationships and social structures in which they operate. Many vertebrate species live in large groups (e.g., fish schools, bird flocks, ungulate herds), but do not exhibit strong social bonds with more than a small number of individuals, and/or the relationships are undifferentiated. Indeed, the "number of differentiated relationships" (Bergman and Beehner, 2015) can vary independently from raw group size. For example, a monogamous pair with bi-parental care involves two differentiated relationships (sexual mate, and caregiving partner) or even three (adding joint territory defense), a situation typical in many birds. The social bonding design features we have identified can operate at multiple levels simultaneously, in the same way that a couple dancing at a party can intensify their own relationship, and their relationship with the broader social group.

\subsection{Participatory versus presentational music}

For most of hominin evolution, the only way to experience music was to make it oneself, or to observe others making music in real time. But as music-making technology culturally evolved, opportunities for solo listening increased (e.g., recording technology, personal music-playing devices) and individual virtuosity became increasingly emphasized. Cross-cultural analyses suggest that forms of music-making coevolved in parallel with social structures: larger-scale, more hierarchical societies tend to emphasize "presentational" music made by small numbers of performers for large numbers of passive (or virtual) audiences. Conversely, smallerscale, more egalitarian societies tend to emphasize "participatory" music in which large groups sing, dance, and play instruments together with little or no distinction between performers and audience (Lomax 1968; Turino 2008). Once group size increases substantially, it may not be feasible for all individuals to participate actively in a coordinated manner, but music can facilitate bonding 
via passive (including digital) participation. This enables music (e.g., national anthems) to help construct social identities even among massive "imagined communities" (Anderson 1991) whose members may never physically interact with one another.

The participatory mode of musical performance is hypothesized to be the ancestral one that operated over long time scales. It is imperative to avoid conflating pervasive technology-driven aspects of contemporary musical practice (e.g. static audiences, solo listening, control by global corporations) with the conditions under which humans experienced music during most of our evolutionary history. As a result, testing predictions of the MSB hypothesis should favor contexts such as drumming circles, campfire singalongs and folk dances over solo-listening via headphones, or collective, static listening at a Mozart performance. Even in societies dominated by presentational music, participatory contexts retain their social and emotional potency, as highlighted by the collective singing of Italians from their balconies during the coronavirus lockdown (Grahn et al. 2020; Horowitz 2020; Kornhaber 2020).

\subsection{Summary}

Summarizing, the MSB hypothesis argues that music is a derived bonding mechanism, akin to but augmenting previous ABMs like grooming and laughter. This augmentation occurs via the provision of a shared framework for individual participants to establish and maintain strong bonds with more than one individual (or a small group of individuals) at a time, thus bridging the "bonding gap" problem posed during human evolution by increasing group size and complexity (Dunbar 1993, 2012b). Proto-musical features may initially have arisen as behavioral innovations that later initiated a process of gene-culture coevolution. Crucially, the design features of music discussed above make music better suited than ABMs or language for coordinating behavior and facilitating social bonding in larger and more complex groups.

\section{Cross-disciplinary evidence}

Evidence in support of the MSB hypothesis comes from cross-cultural, historical/archaeological, developmental and social psychological research.

\subsection{Cross-cultural evidence}

One line of evidence for the MSB hypothesis comes from the study of cross-cultural musical universals (Brown \& Jordania 2013; Lomax 1968; Mehr et al. 2019; Nettl 2015; Savage \& Brown 2013; Savage 2018, 2019b; Stevens \& Byron 2016; Trehub et al. 2018). Music, like language, is a human universal found in all known cultures (Donald Brown 1991; Mehr et al. 2019). Few if any specific musical features are found in all known musics, just as few specific linguistic features are found in all known languages (Evans \& Levinson 2009). However, researchers have identified dozens of "statistical universals" that predominate throughout diverse samples of the world's music, relating both to functional context and to musical structure (Savage et al. 2015; Mehr et al. 2019; Table 1). These cross-cultural similarities suggest selection by biological and/or cultural evolution.

Table 1: Cross-culturally widespread musical structures and functions. Functional contexts were found by Mehr et al. (2019) to be associated with singing in ethnographic descriptions of the 60 societies from the Human Relations Area Files Probability Sample (Lagacé, 1979). Musical structures were found by Savage et al. (2015) to predominate (items 1-18) or to co-occur (item 19) consistently in each of nine world regions across a sample of 304 audio recordings from the Garland Encyclopedia of World Music (Nettl et al. 1998-2002). Nested relationships are indicated with indented italics; *indicates associations that were only significant using one of the two methods reported by Mehr et al. (2019) ${ }^{3}$.

\footnotetext{
${ }^{3}$ Mehr et al. (2019) used two methods to examine universal associations with singing: "topic annotations from the Outline of Cultural Materials ['OCM identifiers'] and automatic detection of related keywords". The second method was needed "because some hypotheses correspond only loosely to the OCM identifiers (e.g., 'love songs' is only a partial fit to ARRANGING A MARRIAGE [the OCM identifier used] and not an exact fit to any other identifier)". Similarly, "group bonding" is only a partial fit to the OCM identifier "SOCIAL RELATIONSHIPS AND GROUPS", which covers a broader range of social behaviors than simply "group bonding". After adjusting for ethnographer bias and multiple comparisons, Mehr et al. found "support from both methods for 14 of the 20 hypothesized associations between music and a behavioral context, and support from one method for the remaining six". See Mehr et al. (2019) for further details.
} 


\begin{tabular}{l|l|}
\hline \multicolumn{2}{|l|}{ Functional context (from Mehr et al. 2019) } \\
\hline 1) Dance & 15) War* \\
\hline 2) Infancy & 16) Praise* \\
\hline 3) Healing & 17) Love* \\
\hline 4) Religious activity & 18) Group bonding* \\
\hline 5) Play & 19) Marriage/ weddings* \\
\hline 6) Procession & 20) Art/creation* \\
\hline 7) Mourning & \\
\hline 8) Ritual & \\
\hline 9) Entertainment & \\
\hline 10) Children & \\
\hline 11) Mood/emotions & \\
\hline 12) Work & \\
\hline 13) Storytelling & \\
\hline 14) Greeting visitors & \\
\hline
\end{tabular}

\begin{tabular}{|c|c|}
\hline \multicolumn{2}{|c|}{ Musical structure (from Savage et al. 2015) } \\
\hline 1) Group performance & 15) Voice use \\
\hline 2) Isochronous beat & 16) Modal register (chest voice) \\
\hline 3) Metric hierarchy & 17) Word use \\
\hline 4) 2-or 3-beat subdivisions & 18) Male performers \\
\hline 5) 2-beat subdivisions & 19) Co-occurrence of: Dance \\
\hline 6) Few durational values $(<5)$ & $\begin{array}{l}\text { accompaniment, Group performance, } \\
\text { Isochronous beats, Percussion }\end{array}$ \\
\hline 7) Motivic rhythms & instruments, Few duration values, \\
\hline 8) Discrete pitches & Motivic rhythms, Repetitive phrases, \\
\hline 9) $\leq 7$ scale degrees & Syllabic singing \\
\hline 10) Unequal scales & \\
\hline 11) Small intervals (<750 cents) & \\
\hline 12) Descending/arched contours & \\
\hline 13) Short phrases (<9s) & \\
\hline 14) Instrument use & \\
\hline
\end{tabular}

Crucial to our hypothesis, music performs similar social bonding functions across cultures. All of the 20 widespread functional contexts supported by at least one analysis in Mehr et al. (2019) summarized in Table 1 relate to social bonding, particularly through the ubiquitous use of music in communal ceremonies and rituals (e.g., healing, procession, mourning, storytelling, greeting visitors, praise/religion, weddings). Even the secular use of music as art or entertainment is itself often a form of communal ritual. For example, aspects of Western art music concert attendance function to cement social bonds between participants and exclude nonparticipants in similar ways to other elite rituals throughout history (Small 1998; Nooshin 2011). Other non-ritual contexts have social bonding functions in bringing together parents and infants (lullabies and play songs), mates (love songs), or coordinating activities among multiple individuals (work songs, dance music). Finally, regulation of moods/emotions is one of the key components of our definition of social bonding ("...synchronizing and harmonizing the moods, emotions, actions or perspectives of two or more individuals"). Even mood regulation via solo music can support social functions or evoke social contexts. For example, people may ease the pain of separation from loved ones by listening to or playing music that evokes shared memories (Kornhaber 2020), or use music to prepare their mood for an effective social interaction, allowing them to regulate their behavior and behave in the sociallyexpected manner (Erber et al. 1996; Greenwood \& Long 2009).

Likewise, most of the widespread structural aspects of music support coordinated music-making. Throughout the world, humans tend to sing, play percussion instruments, and dance to simple, repetitive music in groups, and this is facilitated by the widespread use of simple-integer pitch and rhythm ratios, scales based on a limited number of discrete pitches $(<=7)$, and isochronous beats grouped in multiples of two (Bowling et al., 2015; Ravignani et al., 2016; Jacoby \& McDermott, 2017; Kuroyanagi et al., 2019; Jacoby et al., in prep.; Savage et al. 2015). The widespread use of simple, discrete meters and scales also enables multiple people to memorize and coordinate their performances. These widespread musical properties have few direct parallels in language. Group coordination provides a common purpose that unifies the cross-cultural structural regularities of human music (Savage et al. 2015).

\subsection{Fossil and archaeological evidence}

While music itself leaves no fossil record, inferences can be drawn from evidence about the evolution of musicality, the role this played in early human society, and its relationship to other evolutionary developments such as brain size, language, group size, and sociality (Mithen, 2005; Morley, 2013). The fossil record for human evolution indicates that capacities for sophisticated and diverse vocalizations and body language, including dancing, were present before there is credible evidence for compositional language (as reviewed in Mithen 2005). Archaeological evidence from the Paleolithic indicates increasing group size and long-distance contacts (Gamble 2010; Read and van der Leeuw 2015), suggesting that ABMs had become insufficient by at least two million years ago. The earliest surviving musical instruments - bone flutes - have been dated to over 35,000 years ago and are speculated to have functioned to support larger social networks (Conard et al. 2009). Prehistoric rock art often appears to be positioned with regard to the acoustic 
properties of either the cave or cliff face on which it is located (e.g. Fazenda, F. et al. 2017; Rainio et al. 2018), suggesting that music played a role in the social-bonding rituals associated with that art. Similarly, prehistoric and early historic architecture used for socialbonding ceremonies often appears to have been designed with regard to its acoustic properties and to facilitate music making (e.g. Göbekli Tepe, Notroff et al. 2016; Stonehenge and other Neolithic monuments in Britain, Watson \& Keating 1999; Banfied 2009; Ancient Mayan temples, Sanchez 2007).

\subsection{Developmental evidence}

Extensive evidence demonstrating spontaneous and early development of social functions of music also supports the MSB hypothesis. Adults around the world produce infant-directed songs, such as lullabies, with similar, cross-culturally recognizable acoustic features (Trehub et al. 1993; Mehr et al. 2018). Song is highly effective at emotional modulation in infants - reliably more effective than speech, with infants exhibiting longer visual fixations and greater reductions in stress and body movement to maternal singing than to speaking (Cirelli \& Trehub 2020; Corbeil et al. 2016; Ghazban 2013; Nakata \& Trehub 2000; Trehub 2016). Infants also respond differently to songs sung in different styles (e.g. lullaby, vs. playsong; Cirelli et al. 2019; Rock, Trainor \& Addison, 1999). Singing to infants thus appears to serve a communicative function, allowing parents to communicate specific emotional messages to infants before they can understand the semantic content of language (Rock et al. 1999; Trainor et al.1997; Trehub et al. 1997). Singing and musical interactions also directly improve parent-infant social bonds: Interventions promoting singing and musical interaction between parents and infants strengthen parents' attachment to their infants, more so than nonmusical play (Vlismas et al. 2013). Music thus facilitates both parent-infant communication and parent-infant bonding from early in life, before extensive experience or opportunity for learning.

Beyond infancy, musical activities continue to promote bonding: Across a range of tasks, group musical involvement increases children's prosocial behavior. Thus, young children act more prosocially (in terms of sharing and fairness) after a musical game than a similar non-musical game (Kirschner \& Tomasello 2010); after group singing than group art or competitive games (Good \& Russo 2000); and after joint synchronized, rhythmic movement than non-synchronized movement (Rabinowitch \& Meltzoff 2017).

Children (like adults) choose to affiliate with members of their own social group (Bigler et al. 1997). From early infancy, music serves as a marker of social group membership, allowing for the identification of preferred social partners (Cirelli et al. 2018). Shared knowledge of specific songs serves as a particularly informative signal of common group membership: due to the wide range of forms a song can take, knowledge of a particular song implies common social or cultural background (Soley \& Spelke 2016). Infants accordingly treat shared musical knowledge as socially meaningful from early in life: five-month-old infants prefer to look at people who sing melodies previously sung by a parent, over people who sing melodies previously sung by an unfamiliar adult (Mehr et al. 2016). These early preferences appear to form the foundation for selective social affiliations based on music: at preschool age, children use knowledge of a familiar song as a social cue to select friends (Soley \& Spelke, 2016), and by 14 months exhibit more prosocial behavior (helping) toward an unfamiliar woman who sings a familiar song (previously sung by a parent) than an unfamiliar song (Cirelli \& Trehub 2018). Together, these results suggest that musical knowledge shapes the formation of children's social bonds, and that the link between shared musical knowledge and social connection is rooted in early infancy.

\subsection{Social psychological evidence}

Behavioral experiments from social psychology support the MSB hypothesis, suggesting that musical behavior is not only associated with, but may causally support, social bonding. In particular, music provides a foundation for synchronized behavior in large groups (as argued above), and a number of experiments and meta-analyses show that rhythmic synchronization with other individuals promotes increased prosocial behavior (i.e., actions that increase others' well-being; Mogan et al. 2017; Rennung \& Göritz 2016). Synchrony has been empirically linked to cooperation in economic games (Lang et al. 2017; Launay et al. 2013; Reddish et al. 2014; Wiltermuth \& Heath 2009), entitativity (feelings of being on the same team; Reddish et al. 2013; Lakens \& Stel 2011), rapport and interpersonal liking (Hove \& Risen 2009; Miles et al. 2009; Valdesolo \& Desteno 2011), and helping behavior (Cirelli et al. 2014; Valdesolo \& Desteno 2011; Kokal et al. 2011). Similarly, dancing in synchrony increases participants' feelings of connectedness to the group with which they are dancing, as well as their liking and assessment of similarity with co-dancers (Tarr et al. 2016; Tarr et al. 2015). These prosocial effects of synchrony are robust in different contexts (Mogan et al. 2017). Although demand characteristics have been suggested as possible confounds underlying these effects (Rennung \& Göritz 2016; Atwood et al. 2020), significant prosocial effects of synchrony remain after potential confounds of suggestion, competence and shared intention are eliminated (e.g. in 
a virtual reality setting; Tarr et al. 2018). However, meta-analyses implied inconclusive results regarding the precise roles of "music" and of synchrony to an isochronous beat, as opposed to more generally synchronized or coordinated non-musical behaviors such as gaze synchrony, affect synchrony, and motor synchrony (Mogan et al. 2017; Rennung \& Göritz 2016). In section 5, we propose clearer predictions and tests of specific mechanisms by which music promotes social bonding.

More broadly, behavioral studies indicate varied social bonding effects associated with music-based activities, even those that do not explicitly involve constant synchrony. Young children randomly assigned to activities incorporating music exhibit elevated levels of empathy compared to non-musical controls in longitudinal studies (Rabinowitch et al. 2013), and adults singing in regular group sessions develop feelings of social closeness towards co-participants more quickly than people engaged in other (non-musical) group activities (Pearce et al. 2015). Feelings of inclusion, connectivity and positive affect emerge in small and large singing groups, with participants in large choirs ( $>80$ participants) reporting greater changes in these measures compared to smaller choirs (Weinstein et al. 2016). These findings highlight the relevance of music-based activities for large-scale social bonding.

\section{Neurobiological mechanisms}

The MSB hypothesis proposes that social bonding is the ultimate, functional explanation of the evolution of musicality. We now propose specific hypotheses about underlying neurobiological proximate mechanisms underpinning music's social effects (Fig. 3). In brief, music involves predictable combinations of rhythms and pitches, activating neural mechanisms for perception that are tightly coupled with the motor system. Learning to form predictions about these features activates the dopaminergic reward system, which synchronizes its activity with distal regions within the brain. Crucially, predictability also supports synchronization of homologous regions in other individuals' brains. This "neural resonance" (synchronous brain activity across individuals) facilitates social bonding through shared experience, joint intentionality, and "self-other merging". Through the production of oxytocin and endogenous opioids, neural resonance also facilitates prosociality by associating the rewarding musical experience with specific co-experiencers. Furthermore, because these prosocial experiences are themselves rewarding, we seek them out by attending to and learning more musical features/experiences, updating our predictions (e.g. through statistical learning, by performing and/or experiencing new music), and closing the mechanistic cycle. This proposed mechanistic cycle is detailed below.

a)

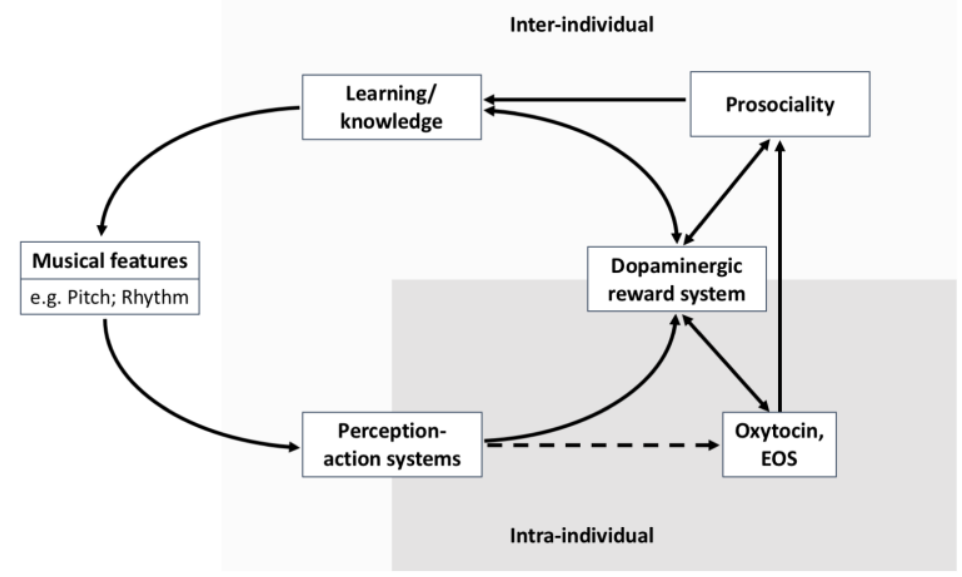

b)

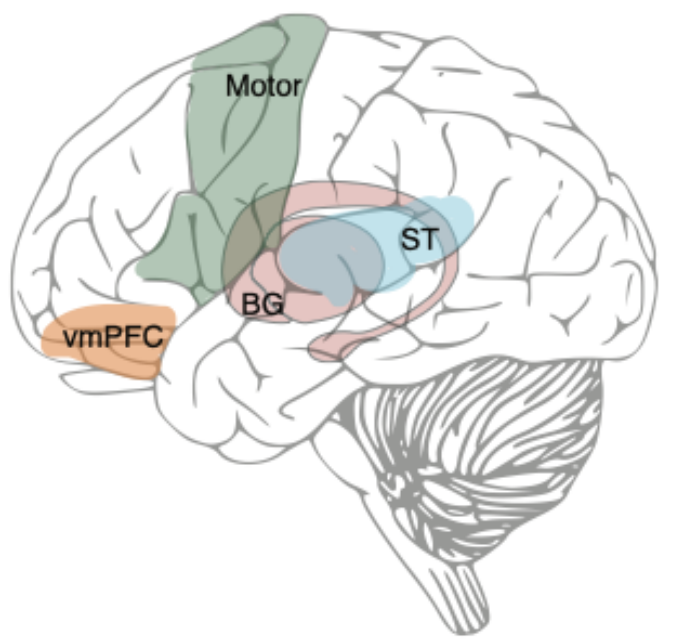

Figure 3. a) Proposed neurobiological mechanisms underlying music's social bonding functions, showing intra- and interindividual levels. We propose that the dopaminergic reward system interacts with the Endogenous Opioid System (EOS) and the release of oxytocin, ultimately providing opportunities for individuals to synchronize their moods, emotions, actions and/or perspectives through musical engagement. (Dashed arrow indicates need for more evidence to confirm that the perception/production of music stimulates this pathway). b) Key neuroanatomical regions in the human brain underlying the MSB hypothesis. ST: superior temporal lobe structures important for auditory perception including Heschl's gyrus, planum temporale, superior temporal gyrus, superior temporal sulcus, middle temporal gyrus. Motor: frontal lobe structures crucial for action planning and execution including premotor and supplementary motor areas as well as primary motor cortex. BG: 
Basal ganglia and related structures, including amygdala, striatum, ventral tegmental area / substantia nigra, caudate, putamen, globus pallidus, nucleus accumbens. vmPFC: ventromedial prefrontal cortex.

\subsection{Perception-action coupling}

Perception-action coupling refers to anatomical and/or functional connectivity between brain regions involved in sensory perception (e.g., of pitch or rhythm) and those that are involved in movement (e.g., vocalization, dance). Specifically, auditory-motor coupling is a key neural mechanism that underlies social bonding through music because it enables individuals to synchronize and/or harmonize their own music and actions with others, which is crucial for coordinated group music making. Even during the perception of solo music, the tight coupling between perceptual and motor regions leads to spontaneous and obligatory activity in premotor and supplementary motor areas, classic motor areas that are also part of the action observation network that drives physical and observational learning (Cross et al. 2008).

Rhythm and beat consistently activate the premotor area, supplementary motor area, and basal ganglia, regions commonly thought to belong to the motor system (Grahn \& Brett 2007). Furthermore, the auditory system is strongly coupled with areas in the motor system during rhythm perception (Grahn \& Rowe 2009), and rhythmic oscillatory activity in both the auditory and motor systems tracks the rhythm of music (Fujioka et al. 2015). Some observations show that neural phase-locking activity is even higher in music than in speech (Vanden Bosch der Nederlanden et al. 2020). This process of "neuronal entrainment" (neural activity changing its frequency, amplitude, and/or phase in response to external stimulation) is a proposed mechanism through which rhythm in sensory stimuli affects the brain by coordinating activity between separate neuronal populations, such as between the auditory and motor systems (Jones 2018; Morillon \& Baillet 2017). This neuronal entrainment enables selective attention to specific points in time (Lakatos et al. 2008; Large \& Jones 1999). In particular, auditory-motor coupling is strongest when perceiving "high groove" music that elicits the pleasurable drive towards action such as in dance (Janata et al. 2012). Groovy music elicits the urge to dance by increasing the auditory cortex's sensitivity and its coupling with the motor cortex (Stupacher et al. 2013), which is particularly evident with medium levels of rhythmic complexity and expectation violation (Witek et al. 2014; Koelsch et al. 2018). In this respect, dance or any movement to music - is inextricably linked to musical experiences. Note, however, that like many of the mechanisms proposed here, coding of value in sensory cortices (i.e., a stronger sensory response to more important or rewarding stimuli) is not unique to the auditory domain but is also evident in other sensory domains such as vision (Koelsch et al. 2018).

An important pathway underlying perception-action coupling is the arcuate fasciculus, a bundle of axonal connections between frontal lobe (including motor areas) and superior temporal lobe (including auditory areas). Abundant neuroimaging evidence supports the role of the arcuate fasciculus in music making, specifically in auditory perception-action coupling (Loui et al. 2009, 2011; Halwani et al. 2011; Moore et al. 2017; Sammler et al. 2015). This same pathway also plays a role in social functions: more emotionally empathic people have higher microstructural integrity within the arcuate fasciculus (Parkinson \& Wheatley 2014). In contrast, people on the autism spectrum, who have known impairments in social bonding, have less connectivity in the arcuate fasciculus (Fletcher et al. 2010; Wan et al. 2010). By enabling perception-action coupling, the arcuate fasciculus thus provides one possible shared neural mechanism between music and social bonding.

\subsection{Prediction and the dopaminergic reward system}

Musical perception-action coupling sets up repeated cycles of prediction, expectation violation, and resolution (Huron 2006). In these hierarchical perception-action trajectories, the predictive context surrounding pitch and rhythm are established, violated, and then resolved (Fitch et al. 2009; Clark, 2013). Successful predictions become rewarding to the brain by activating neurons of the dopaminergic system and its related areas (caudate, nucleus accumbens, amygdala, and ventromedial prefrontal cortex) that code for fundamental evolutionary rewards such as food and sex, and also learned rewards such as money (Friston 2010; Schultz et al. 1997; Knutson et al. 2000). The same dopaminergic reward system is also active during the anticipation and perception of pleasurable music (Blood \& Zatorre, 2001; Blood et al. 1999; Salimpoor et al. 2011, 2015; Zatorre \& Salimpoor 2013; Zatorre 2018; Cheung et al, 2019), supported by the functional coupling between auditory areas in the superior temporal lobe and reward-sensitive areas such as the nucleus accumbens (Salimpoor et al. 2013). Manipulating expectations for pitch-related musical features, such as consonance and dissonance, can modulate activity in the nucleus accumbens and amygdala. Thus, music can provide its own reward prediction error and motivate learning (Gold et al. 2019; Cheung et al, 2019). Additionally, people who frequently experience chills when listening to music show high white matter connectivity between auditory, social, and reward-processing areas (Sachs et al. 2016). Chills from 
music are also related specifically to increased binding to dopamine receptor D2 (Salimpoor et al., 2011). In contrast, people with musical anhedonia, who find music unrewarding, have decreased functional connectivity and altered structural connectivity between auditory and reward-related areas (Loui et al. 2017; Martínez-Molina et al. 2016; Mas-Herrero et al. 2014).

Because humans are social animals, the predictions we make and the rewards we receive are often tied to social stimuli. Thus, the brain has to learn from social cues by associating social stimuli with reward predictions (Atzil et al. 2018). Indeed, the same areas in the dopaminergic reward system - the caudate, nucleus accumbens, and ventromedial prefrontal cortex - are causally linked to cooperative behavior as well as prediction and reward. The reward system is activated when we share information with others about ourselves (Tamir et al, 2012), when we view loved ones (Bartels and Zeki, 2004), and when mothers bond with their infants (Atzil et al. 2017). Prosocial behaviors commonly engage the reward system (Zaki \& Mitchell 2013); these include cooperating (Decety et al. 2004), perspective taking (Mitchell et al. 2005), and empathizing with others (Beadle et al. 2018). Together, these results suggest that the dopaminergic reward system is involved causally in the link between music and social bonding through the mechanism of prediction.

\subsection{Oxytocin and the Endogenous Opioid System (EOS)}

We propose that opioids released in the EOS, and oxytocin, are also part of the mechanistic underpinnings linking prediction, reward, and social bonding (Chanda \& Levitin 2013; Launay et al. 2016; Tarr et al. 2014). The nucleus accumbens and ventral tegmental area are key regions that overlap between the dopaminergic reward system and the EOS (Le Merrer et al. 2009; Dölen et al. 2013), and dopamine is thought to be a salience processing mechanism regulated by oxytocin (Love 2014; Shamay-Tsoory \& Abu-Akel 2016).

The EOS likely plays a mechanistic role in music-related prosociality. This system has been implicated in the maintenance of social bonds in primate social networks (Keverne et al. 1989; Maestripieri 2010; Ragen et al. 2013; Schino \& Troisi 1992). Intervention studies in humans indicate that, compared to a placebo, naltrexone (an opiod blocker) can reduce feelings of social connections with others (e.g. Inagaki 2018, Inagaki et al. 2016), and lower affiliative behaviour and desire for interpersonal closeness (Tchalova \& MacDonald 2019). Listening to music influences mu-opiate receptor expression in the EOS (Stefano et al. 2004) and can reduce the need for pain medication ${ }^{4}$ (e.g. Lepage et al. 2001; Bernatzky et al. 2011). Elevated pain thresholds are experienced after singing (Pearce et al. 2015; Weinstein et al. 2016) and synchronized dancing (Tarr et al. 2015; Tarr et al. 2016), but not after administration of naltrexone (Tarr et al. 2017), suggesting that pain threshold is an appropriate proxy-measure of endorphin uptake in these experiments. There is some evidence of endorphin-mediated synchrony effects on cooperation (e.g. when dancing; Lang et al. 2017), further demonstrating links between music, the EOS, and social bonding.

Although more empirical work is needed, there is evidence that oxytocin levels are elevated after taking part in a singing class (Grape et al. 2003), or following a group jam session of improvised singing (Keeler et al. 2015). Elevated oxytocin levels have been correlated with increased generosity (Zak et al. 2007, Fujii et al. 2016), empathy (Domes et al. 2007, Hurlemann et al. 2010), and possibly trust (Kosfeld et al. 2005; Zak et al. 2005, but see Nave et al. 2015 and Declerck et al. 2020). Furthermore, intranasal administration of oxytocin promotes in-group cooperation (e.g., De Dreu \& Kret 2016) and increases synchrony in dancing (Josef et al. 2019) and finger-tapping behavior (Gebauer et al. 2016), suggesting a reciprocal feedback loop between music-based activity and social cohesion. Although evidence linking oxytocin specifically with music remains limited, and the strength of oxytocin's relationship with cooperation more generally is debated (particularly studies based on administering intranasal oxytocin; e.g. Walum et al. 2016), current evidence suggests that music engages the oxytocin and EOS systems in ways that facilitate social bonding, as predicted by the MSB hypothesis. Combined with the reward system, these pathways offer a positive-feedback loop following music engagement, enabling groups of individuals to synchronize their moods, emotions, actions and/or perspectives, and providing motivation to continue engaging with others in social and musical contexts.

\subsection{Learning and vocal imitation}

The capacity to learn and reproduce complex motor movements, including vocalizations (songs), is central to the cultural transmission of music. Although humans are the only primates capable of learning complex, novel vocalizations, this ability has evolved

\footnotetext{
${ }^{4}$ Endogenous opioids (e.g. beta-endorphins) likely interact with other systems in analgesic effects (e.g., Welch \& Eads 1999). Nevertheless, elevated pain threshold is a common proxy-measure of elevated beta-endorphin levels, due to the EOS's role in our pain-pleasure circuitry (Mueller et al. 2010), and the fact that direct measures are invasive and expensive.
} 
independently at least seven times in evolutionary history (Fitch \& Jarvis 2013; Nowicki \& Searcy 2014; Syal \& Finlay 2011), allowing us to make inferences about how and why it evolved. Some vocal learning clades (seals, baleen whales, and some songbirds) show a strong male bias in vocal learning abilities consistent with sexual selection. However, such a bias is absent in most other vocal learners (parrots, elephants, toothed whales, many tropical bird species, and humans), suggesting that sexual selection cannot be the only factor driving the evolution of vocal learning (Fitch 2006). Instead, learned animal songs (solo or duet) appear to serve multiple evolutionary functions within the umbrella of social bonding, including mate attraction, cementing and affirming social bonds within pairs or groups, and territorial functions including advertising the bonded group's ability to repel outsiders (Haimoff 1986; Wickler 1980; Geissmann 1999).

In vocal learning species, vocal imitation and song production are likely based on similar neurobiological mechanisms (Mercado et al. 2014). Learning to reproduce pitches and rhythms accurately engages reward mechanisms, as shown by evidence that dopamine neurons encode performance error in songbirds (Gadagkar et al. 2016). Furthermore, the presence of a conspecific (of the opposite sex in this case) leads the male zebra finch to decrease variability of sung syllables; this syllabic structure is attributed to perception-action circuits analogous to the human superior temporal and motor structures (Sakata \& Brainard 2008; Fitch \& Jarvis 2013). Once individuals learn to produce musical features, they not only reproduce learned patterns of features, but also deviate from predicted combinations of features, for example by inventing new melodies (Wiggins et al. 2018).

\section{Predictions for future research}

The MSB hypothesis predicts that core design features of music make it particularly well-suited to facilitate social bonding, and particularly effective in the bonding of large, complex groups. This leads to the following testable predictions:

\subsection{Cross-domain predictions (music, language, ritual, etc.)}

The MSB hypothesis predicts that music (including dance) is better-suited to social bonding of large, complex groups than ABMs (grooming, laughter), language, or other non-acoustic bonding mechanisms like shared decorations or non-musical ritual behaviors (e.g., praying together without music). Music should be more effective and/or efficient relative to other methods as group size and complexity increase, such that while making music in pairs might only produce a small increase in dyadic bonding relative to conversation, making music in larger, more complex groups of people (dozens or hundreds organized into differentiated sub-groups) should be more effective for collective bonding than language, laughter, grooming, etc.

In a social species like humans, many activities can develop and enhance social bonding, but we predict that bonding via non-musical methods like language, ritual, or sports should be enhanced by the addition of musical components (e.g., religious services with group singing will result in stronger bonding than those that only involve group prayer). Different musical components are predicted to have synergistic effects such that - all things being equal - including more of these components (e.g., synchronized, harmonized singing and dancing in groups) will tend to increase bonding more than activities that only use one or a few (e.g., conversations or recitation in pairs $)^{5}$. We also predict that participatory musical performances will have significantly stronger effects than either non-participatory (e.g., performance for a static audience) or solo musical experiences (e.g., listening alone to recordings). Group size and complexity should have independent effects (e.g., singing in large choirs should produce greater bonding than singing in small choirs).

These predictions can be tested in controlled experiments and/or field studies along the lines of those discussed in section 3. Designing studies that control for specific similarities and differences between closely related domains such as music, language, and dance is challenging but not impossible. For example, to control for the fact that languages have their own (non-isochronous) rhythms, Savage et al. (2020) had groups of participants simultaneously recite the lyrics to "Twinkle, Twinkle, Little Star" to an isochronous beat or in non-isochronous free rhythm. Savage et al. (2020) also propose additional manipulations that would allow this paradigm to test other specific predictions of the MSB hypothesis regarding the social bonding effects of melody, harmony, and dance (cf. Fig. 3 in Savage et al. 2020).

\footnotetext{
${ }^{5}$ However, other factors (e.g., ceiling effects, optimal degrees of complexity, rhythm-melody interactions [Prince et al. 2009]) may limit social bonding effects, leading to non-linear interactions when combining multiple musical components.
} 


\subsection{Cross-cultural predictions}

The MSB hypothesis predicts that music's social bonding functions should be distributed widely in space and time. Hence, the kinds of predictions described in section 5.1 regarding music's superior social bonding power in large groups should apply consistently across cultures and throughout history. Furthermore, it predicts that musical contexts and structures that promote social bonding (e.g., coordinated, participatory group performances) will be more common across cultures than music produced by and for individuals. At the same time, the relative importance of participatory vs. presentational music-making is predicted to vary cross-culturally as a function of social structure (due to limitations on simultaneous coordinated performance discussed in section 2.5). Smaller-scale, more egalitarian cultures should thus perform and value participatory music more than larger-scale, hierarchical cultures where presentational music should be more common and valued. Participatory vs. presentational distinctions are analogous to those found in "imagistic" (high-intensity, small-scale) vs. "doctrinal" (low-intensity, large-scale) religious rituals, respectively (Whitehouse 2004), and are predicted to covary cross-culturally with these modes of religiosity. Even in cultures where music is often consumed passively by individuals (e.g. in Western culture, over headphones on personal listening devices), MSB predicts that music will be more effective than non-musical alternatives for social bonding purposes (cf. Rentfrow \& Gosling 2006). These predictions about crosscultural use of music for social bonding could be tested in cross-cultural behavioral experiments (cf. Henrich et al. 2006; Polak et al. 2018; Jacoby et al. in prep) or analysis of cross-cultural databases of recordings, artefacts, ethnographies, or questionnaires (cf. Lomax 1968; Mehr et al. 2019; Savage et al. 2015; Savage 2019c; Whitehouse et al. 2019; Wood et al. In prep).

\subsection{Cross-species predictions}

The MSB hypothesis proposes that human musicality has been shaped by biological and cultural selection, and that the features of music are particularly well-suited for social bonding functions because they support extended, coordinated group performances on a large scale. The MSB account does not claim that music's social bonding function is a unique biological adaptation specific to human musicality. Instead, it argues that music-like behaviors should enhance existing bonding mechanisms in other species as well. Thus, it predicts that, rather than an all-or-nothing divide between human and non-human "music", species will vary continuously in the degree to which they share specific features of human musicality. The social bonding functions associated with different components of musicality should operate similarly across species, depending on the specific subcomponent, its suitability for group coodination, and the importance of social bonding to their species.

Thus, melodic, learned song among songbirds, whales, or other vocal learners are predicted to enhance social bonding in these species in a manner analogous to song in humans. These effects may be limited in many non-human species by their lack of ability and/or interest in performing in coordinated groups (e.g., some primates appear motivated to conduct group displays but are unable to synchronize to a beat, while some birds appear able to move to a beat but are unmotivated to do so in groups in the wild; Hoeschele et al. 2018). However, such effects should be pronounced in species that perform duets (e.g. many birds, and duetting primates such as gibbons or titi monkeys; Hall 2004; Haimoff 1986). Conversely, social primates that do not typically perform in coordinated groups may nonetheless experience social bonding effects of "group" music when exposed to versions of their own vocalizations that have been artificially manipulated to be in synchrony/harmony. Such production/perception dissociations and other nuances of musicality could be tested in controlled cross-species experiments (cf. Hoeschele et al. 2018; Merchant et al. 2018).

The MSB hypothesis posits that music and musicality provided a major means by which humans could coordinate behavior on a larger scale than dyads or small groups, allowing for the formation of larger socio-cultural groups. If true, and if different species share components of musicality to differing degrees, then across species, production or proficiency in "musical" behaviors should predict both the number and complexity of social bonds. For example, gelada baboons live in unusually large and complex groups for primates, and they also exhibit rhythmic and melodic vocal features that are unique among primates (Richman 1978, 1987; Gustison et al. 2012; Bergman 2013). Like geladas, many parrot species live in large fission-fusion social groups, and members of the parrot clade show vocal imitation, call convergence, duetting, and the capacity for rhythmic synchronization (Bradbury 2001; Balsby \& Scarl 2008; Scarl \& Bradbury 2009; Schachner et al. 2009). In both of these clades, pairs or mating "harems" form stronger bonds than those they share with the larger groups in which they are embedded (cf. Wanker et al. 2005; Balsby \& Scarl 2008). Other species that live in complex fission-fusion groups and could provide evidence of specific design features are elephants and some odontocetes (e.g., orcas, bottlenose dolphins). Such species live in large, complex fission-fusion groups, and are documented vocal learners, but their possession of other design features of music (e.g., synchronization) have not been tested rigorously. 
For many species, evidence for design features of musicality would count as evidence against our hypotheses. Examples include solitary species (e.g. many reptiles), for whom groups consist only of mothers and dependent young (e.g. many carnivores), or group living species that do not have differentiated social bonds with other group members (e.g. schooling fish, larger herds, swarming insects).

The MSB hypothesis further predicts that if a species does not follow this pattern (e.g. by having a larger social group size than predicted by their features of musicality), then that species will have evolved other non-musical but effective means of coordinating behavior that likely do not appear in human behavior (e.g., reproductive suppression in naked mole rats or pheromonal queen control in eusocial insects; Alaux et al. 2010; Dengler-Crish \& Catania 2007). Thus, although the social bonding design features seen in human musicality are not the only way to achieve large, well-bonded groups, they are effective enough that we predict them to evolve convergently (cf. Fitch 2006).

\subsection{Neurobiological predictions}

The MSB hypothesis predicts that each of the mechanistic factors proposed above (Fig. 3) contributes to the effects of music on social bonding. Alterations of these mechanistic pathways should therefore produce specific, quantifiable results on bonding. For example, music's perceived social bonding functions should correlate with oxytocin/EOS production, and disrupting the oxytocin/EOS pathway via blocking oxytocin or opioid receptors should disrupt its social bonding effects. Furthermore, since the dopaminergic reward system is at the center of prediction for musical features, populations with deficient dopaminergic activity may have impaired predictions, which could affect their ability to synchronize or harmonize with others. On the other hand, drugs that restore dopaminergic functions are hypothesized to restore these abilities, and due to the reciprocal nature of these interactions, activities that enhance predictions (such as dancing and harmonizing) may in turn restore dopaminergic functions. These predictions are being tested in the case of Parkinson's Disease, which is a special population with deficient dopaminergic activity (Grahn et al. 2009; Cameron et al. 2016).

Another prediction is that special populations with high sociability may respond well to musical features especially when coupled with social stimuli, as in the case of children with Williams Syndrome (Lense et al. 2014; Jarvinen-Pasley et al. 2010). At a neural level, music's social bonding function should correlate with the degree of neural connectivity between the perception-action and predictionreward networks, and disruptions to this network (e.g., lesions or genetic syndromes) should accordingly disrupt music's social bonding effect. For example, people with musical anhedonia, who have disrupted connectivity between auditory prediction and reward networks (Belfi \& Loui 2019), are predicted to have weaker social bonds, and genetic differences (e.g. in DRD2) may predict variation in bonding experienced through musical activities. Although some of these predictions may be difficult to test ethically in humans through controlled experiments, many can be tested using neuroimaging combined with neuropsychological testing in special populations, as well as correlational, longitudinal, or intervention (including brain-stimulation) studies, genome-wide association studies, and/or animal models that share specific neurobiological endophenotypes (Finlay et al. 2001; Fitch \& Javis 2013; Gingras et al. 2018; Hoeschele et al. 2018; Niarchou et al. 2019) ${ }^{6}$.

\section{Potential criticisms}

Having detailed our social bonding hypothesis and its predictions, we wish to preempt several potential criticisms.

\subsection{Music, language, and domain-specificity}

The key criticism that we anticipate regards the degree to which the evolution of musicality and social bonding are uniquely and causally linked. Few would deny that music can facilitate social bonding via neurobiological mechanisms that are evolutionarily adaptive. However, whether music is a domain-specific evolutionary adaptation for social bonding, as opposed to a byproduct of the evolution of other adaptations, is open to debate. Language, in particular, has been proposed as an evolutionary adaptation that led to musicality as a byproduct (Pinker 1997; Patel 2008) ${ }^{7}$. Importantly, many researchers have noted that, while there are clear differences

\footnotetext{
${ }^{6}$ We have refrained from making detailed predictions about genetic bases of musicality because our current state of knowledge is limited (Gingras et al. 2018). However, we are hopeful that new findings from initiatives such as the 2019 symposium on "Deciphering the biology of human musicality through state-of-the-art genomics" (http://www.mcg.uva.nl/musicality2019) will enable researchers to investigate genetic dimensions of the geneculture coevolutionary mechanisms we describe.

${ }^{7}$ Others view language evolution as being driven largely by cultural evolution (e.g. Jablonka et al. 2012; Kirby 2017).
} 
in the structure and processing of music and language, there is extensive overlap ranging from structural content (e.g., "musilinguistic continua" between speech and song including intermediate forms like poetry and chant) to neurobiological substrates (e.g., similar neural substrates for processing of pitch, rhythm, and syntax; Brown 2000b, 2017; Fitch 2006; Patel 2008; Peretz \& Coltheart 2003; Peretz et al. 2018; Savage et al. 2012). Indeed, many have proposed that the evolution of musicality may have paved the way for the evolution of language (Darwin 1871; Brown 2000b, 2017; Fitch 2010; Mithen 2005; Shilton et al. 2020).

We accept that our present level of understanding is insufficient to demonstrate conclusively that music coevolved uniquely with social bonding independent from language or other social behaviors. Accordingly, in Section 5 we proposed future investigations of such relationships. However, the fact that music and language are both found universally in all known societies (Donald Brown, 1991; Mehr et al. 2019) suggests that both music and language independently fulfill more fundamental adaptive functions than technologies or cultural artifacts that are not cross-culturally universal.

We make no claim that the mechanisms discussed here are entirely specific to music, or that "musicality" is modular in either the cognitive or neuroscientific senses of this term. For example, prediction and predictive coding are ubiquitous features of vertebrate brains (Schultz \& Dickinson 2000; Clark 2013), by no means specific to musicality. However, music affords a uniquely effective scaffolding framework, including rhythm and harmony, within which neural prediction (and occasional expectation violations) can unfold (Hanslick 1858; Huron 2006; Fitch et al. 2009; Koelsch et al. 2019). Similarly, synchrony is widespread in human sociality (including phenomena such as gaze synchrony, affect synchrony, the chameleon effect, and others), but the isochrony of musical rhythm provides an unusually effective affordance for synchronization. Furthermore, phenomena like "groove" seem to be mainly evoked by musical stimuli, and therefore are relatively domain-specific. Thus, musicality encompasses multiple mechanisms that vary in their domain-specificity, but combines them into a uniquely effective package.

\subsection{Group selection}

Most previous social bonding theories of music evolution have relied on an evolutionary mechanism incorporating some form of group selection, in which genetic variants are selected for due to their effects on the reproductive success of entire groups (e.g., Brown 2000a, Wiltermuth \& Heath 2009). Group selection was largely dismissed for decades (Williams, 1966), and while it is re-emerging in the form of multi-level selection (Wilson \& Wilson 2007; Traulsen \& Nowak 2006) and cultural group selection (Richerson et al. 2016), it remains controversial (Pinker, 2012; see also commentary accompanying Richerson et al. 2016).

The MSB hypothesis does NOT require group selection (any more than grooming, play, or laughter do): fitness advantages accrue to individuals who are able to bond more effectively with larger numbers of individuals. Although there are often advantages to wellbonded groups for various activities (e.g. group hunting or foraging, jointly repelling enemies), even for such activities the key fitness advantages accrue to individuals.

\subsection{Gene-culture coevolution and causality}

Some evolutionary psychologists have been critical of social bonding theories of music evolution because they consider them circular arguments that fail to explain the ultimate causal mechanism by which music could have evolved as a biological adaptation:

Perhaps singing lullabies soothes babies; perhaps dancing relieves tension; perhaps shared stories bond the community. The question is, why would anyone have predicted, a priori, that people would be constituted in such a way that these things would happen? (Pinker 2007, pp. 170-171)

Several have posited an adaptive function for music in enhancing "cohesion" or "bonding"... But this reasoning is circular: it takes as a given the fact that music performance and listening produces reliable effects... and then argues that one or more parts of the music faculty evolved in order to produce these effects. But why should music produce these effects and not others?.... accounts invoking cohesion and/or bonding as an adaptive target provide neither a specific account of the ultimate functional mechanism by which music should increase cohesion, nor an account of how that cohesion would produce fitness advantages. And if cohesion is indeed fitness enhancing, why should individuals wait for music-making to produce that cohesion? Why not just be cohesive without music? (Mehr \& Krasnow 2017, p.676) 
Music does not directly cause social cohesion: rather, it signals existing social cohesion that was obtained by other means (Mehr, Krasnow, Bryant, and Hagen This issue, p. ?? [emphasis in original]; paraphrasing Hagen \& Brant 2003, p. 30)

Our preceding account provides a priori arguments detailing why and how specific design features of human musicality have social bonding effects, the mechanisms underlying these effects, and how and why these may have evolved. In particular, we provided specific reasons that behaviors with the design features of music would have social bonding effects: because such behaviors allow people to predict, synchronize, share goals, distinguish individual contributions, experience shared positive emotions, and make social decisions more than other human behaviors (ABMs or language). This explains why music should produce "[social bonding] effects and not others": behaviors that allow us to align in time and frequency, coordinate behaviors in large groups while distinguishing individual contributions, share emotions and goals, and choose appropriate social partners have tangible and predictable social bonding effects. Music is a particularly effective cognitive "technology" (Patel 2008, 2018) that fulfills these design criteria, making musicality an effective toolkit for social bonding functions, shaped by both biological and cultural evolution.

Our hypothesis differs from most traditional social bonding theories because we do not argue that musicality necessarily originated as a biological adaptation. Instead, components of musicality may have arisen initially as cultural inventions and/or byproducts of other adaptations, later exapted and modified through gene-culture coevolution for their social bonding functions in a musical context (e.g., beat synchronization initially as a byproduct of the evolution of vocal learning, as argued by Patel et al. 2009 and Schachner et al. 2009, although cf. Merker et al. 2018 for an alternative interpretation). The initial social cohesion functions may not have begun as genetic adaptations. In this sense, we largely agree with Mehr et al., who write:

We also agree with proponents of the social bonding hypothesis that musical abilities evolved because musical performances played an important role in cooperative sociality. But given the issues described above, we find it more likely that music evolved to credibly signal decisions to cooperate that were already reached by other means, not to determine them.. (Mehr et al. This issue, p. ??)

But in a social environment in which social bonding already enhanced individual reproductive fitness, the subsequent cultural evolution of musical behaviors would lead to biological selection on musicality (e.g. to promote motivation to engage in/ attend to musical behaviors), because of the adaptive consequences of musicality for social bonding. In this way, just as social bonding is crucial in most primates, generating selection on the mechanisms that achieve it, social bonding functions of "proto-musical" mechanisms may have played important roles in hominin evolution long before today's full-blown musicality evolved.

We emphasize that past adaptive function, while important, should not be the sole criterion by which to judge theories of the evolution of musicality. As previously argued at length (e.g., Fitch 2006, 2015b; Honing et al. 2015), Tinbergen's (1963) multi-factorial perspective, which seeks understanding of traits at the four interlinked explanatory levels of mechanism, ontogeny, phylogeny and adaptive function, is a fruitful method for understanding the evolution of musicality. We may never know with certainty the precise ancestral adaptive conditions or specific genetic mutations involved in the evolution of musicality. Even so, the comparative method provides a key tool for empirically testing evolutionary hypotheses (Fitch 2015b). Section 5 lists a variety of testable empirical predictions of the MSB hypothesis.

\subsection{Parochial altruism and outgroup exclusion}

Enhanced social bonding between some individuals inevitably means a relative decrease between others. In-group social bonding has a dark side of increasing hostility towards outgroups (Whitehouse 2018; Gelfand et al. 2020), as exemplified in the use of music in warfare by the Nazis and other groups throughout history (Brown \& Volgsten 2006). The traditional Maori haka "Ka Mate" is famously used by New Zealand's national rugby team to simultaneously bind team-mates together and intimidate the opposing team through coordinated dancing and vocalization (Jackson \& Hokowhitu 2002). The ability of music to exclude out-group members might appear to be an argument against its function in bonding in-group members, but outgroup exclusion is entirely consistent with the social bonding hypothesis. Because the creation or strengthening of a social bond between some (participating) individuals by definition excludes others, the observation that particular forms of music can cause emotional dissonance or fear in others is compatible with a social bonding function.

Earlier expositions of the social bonding hypothesis (Brown 2000a; Freeman 2000) noted that "bonding is always exclusionary" and "individuals who do not 'belong' become enemies... The process is similar to sexual jealousy, which manifests the exclusionary nature of the pair bond" (Freeman 2000:421-2). This observation is mirrored in the recent literature on oxytocin which, far from being an indiscriminate "love drug," simultaneously exerts affiliative effects among in-group members and exclusionary effects towards out- 
group individuals (cf. Beery 2015; Shamay-Tsoory \& Abu-Akel 2016). The use of music to exclude others is no argument against its social bonding origins.

\subsection{Solo music, sexual selection, and individual signaling}

While coordinated group performances predominate throughout the world, various widespread musical genres are not necessarily performed in coordinated groups. In particular, lullabies and love songs are found throughout the world and are often performed by a lone singer (Trehub et al. 1993; Mehr et al. 2018). This is perfectly consistent with the MSB hypothesis, as lullabies and love songs are often dyadic: sung by a soloist to bond with another person (by soothing an infant or wooing a potential mate).

More generally, some may wonder if social bonding is so important to the evolution of musicality, why do people enjoy playing or listening to music alone? We emphasize that even solo music listening can support social bonding goals (Trehub et al. 2018). A young adult meeting a new person in an online chat discusses music preferences more often than other topics, and based on music preferences alone, people draw social inferences about others (Rentfrow \& Gosling 2006). Thus, music preferences developed during solo listening can be used as social cues, displayed and evaluated when establishing new social bonds.

Solo listening may serve other, non-social functions (e.g. mood regulation, staying awake while driving; DeNora 2000; North et al. 2004; Sloboda et al. 2001). We do not argue that social bonding is the only possible function of music. By analogy, language's primary function may be to communicate information between people, but it is also useful in private thought, or to allow one to preserve thoughts for the future (particularly after the invention of writing). Likewise, the same auditory-motor-reward connections that make music so socially powerful also allow people to enjoy playing or listening to music alone. Often, solo music was experienced previously in a social context, which is re-evoked by solo listening/playing.

Related to the idea of virtuosic solo music-making is the distinction between social bonding and theories such as sexual selection or honest signaling that emphasize music as a signal of individual fitness. The MSB hypothesis does not reject such theories. Instead, it emphasizes that individual signaling theories are insufficient to explain all of the broader social functions of music, while social bonding provides more explanatory power (although we concede that the MSB hypothesis cannot explain all possible functions of music; Oesch 2019). For example, in contemporary Western night clubs and traditional non-Western societies, all-night music and dance rituals function both to bond participants and as opportunities to find potential mates (Merriam 1964; Thornton 1995). In such contexts, dancing, singing, and/or playing instruments can function to bond with same and opposite-sex partners and to advertise evolutionary fitness to potential mates. Bonding and signaling hypotheses are not mutually exclusive, but rather complementary.

The complementarity of the MSB and alternative hypotheses makes it challenging to falsify the MSB hypothesis. However, we have provided a number of specific predictions, each of which is potentially falsifiable and would count as evidence against the MSB hypothesis, particularly if alternative hypotheses better predict the data. For example, our hypothesis and Hagen \& Bryant's (2003) coalitional signaling hypothesis make predictions regarding synchrony: we argue that synchrony should enhance social bonding, while Hagen \& Bryant argue that synchrony should enhance perceived coalitional quality. To differentiate between these and other competing hypotheses, our predictions regarding the effects of synchrony (or other aspects of musicality) on social bonding could be compared directly against perceived coalition quality or other competing predictions (e.g., attractiveness; Miller 2000, parental investment; Mehr \& Krasnow 2017; Mehr et al. this issue) in future research. If synchrony increases perceived bonding relative to perceived coalition quality, attractiveness, or parental investment, it would constitute evidence favoring the MSB hypothesis over competing alternatives. Another example of predictions that differentiate among alternative hypotheses is the MSB predictions that social bonding functions will be common cross-culturally but the relative frequencies of specific genres and sub-functions (e.g., lullabies vs. love songs vs. group dancing) will vary across societies. In contrast, theories that focus on infant-directed song or sexual selection predict instead that these categories should be more common and consistent cross-culturally than the other categories of social bonding. Furthermore, phylogenetic or other cross-species analyses (e.g., Shultz et al. 2011; Hoeschele et al. 2018 ; Schruth et al. In press) could allow us to quantify the relative effects of group size, sexual competition, parental investment strategies, or other factors on the evolution of vocal learning, beat perception, or other aspects of musicality. We encourage tests of MSB predictions against those of competing hypotheses. 


\section{Conclusion}

Social bonding has long been acknowledged as an important function of contemporary music, but its causal role in the evolution of music has often been dismissed as a naïve application of group selection theory. Recent advances in gene-culture coevolution theory allow us to provide a more nuanced model of music evolution that does not rely on group selection. Our argument has focused on social bonding as the primary factor shaping the evolution of human musicality. This MSB hypothesis provides a framework for understanding the past evolution of musicality, and a starting point for the future cultural evolution of new forms of music that harness the social power of music to bring people together. Music may not be a "universal language" (Longfellow 1835; Savage 2019b), but music's universal power to bring people together across barriers of language, age, gender, and culture sheds light on its biological and cultural origins, and provides humanity with a set of tools to create a more harmonious future - both literally and figuratively.

\section{Acknowledgments}

This paper originated in an invited symposium entitled "The origins of music in human society" held in December 2017 at the Abbaye de Royaumont, France, organized by Paul Seabright, Francis Maréchal, Marie-Hélène Cassar, and Juliette Lobry. We gratefully acknowledge funding for the workshop from the French Agence Nationale de la Recherche (under the Investissement d'Avenir programme, ANR-17-EURE-0010). We thank the organisers, sponsors, and other invited participants (in addition to the seven of us, these were: Simha Arom, Kofi Asante, Jean-Julien Aucouturier, Greg Bryant, François Cam, Didier Demolin, Edward Hagen, Nori Jacoby, Martin Lang, Jacques Launay, Samuel Mehr, Marcel Peres, Benjamin Purzycki, Lauriane Rat-Fischer, Nick Rawlins, Sandra Trehub, Connor Wood, and the Ensemble Organum) for this stimulating interdisciplinary workshop and discussion leading to this article and a separate article by Mehr, Bryant, Hagen, and Max Krasnow. We thank Greg Bryant, Shinya Fujii, Eva Jablonka, Nori Jacoby, Kimberly Kobayashi-Johnson, Samuel Mehr, Bjorn Merker, Aniruddh Patel, Peter Pfordresher, Manvir Singh, Dor Shilton, Parker Tichko, Sandra Trehub, the students of Keio University's CompMusic and NeuroMusic Labs, and of Oxford University's Institute of Cognitive and Evolutionary Anthropology, and four anonymous reviewers for comments on earlier versions of this manuscript.

PES was supported by Grant-in-Aid \#19KK0064 from the Japan Society for the Promotion of Science and startup grants from Keio University (Keio Global Research Institute, Keio Research Institute at SFC, and Keio Gijuku Academic Development Fund). PL was supported by the National Science Foundation NSF-STTR \#1720698 and startup funds from Northeastern University. BT was supported by funding from the French Agence Nationale de la Recherche (under the Investissement d'Avenir programme, ANR-17-EURE-0010) whilst on a Visiting Fellowship at the Institute of Advanced Study Toulouse.

AS was supported by the National Science Foundation under NSF-BCS \#1749551.

WTF was supported by Austrian Science Fund (FWF) DK Grant 'Cognition \& Communication' (W1262-B29).

\section{Author contributions}

PES proposed the article concept and author list with feedback from WTF and LG. PES, WTF, and PL drafted the abstract and outline, with feedback from LG, AS, and BT. WTF, PES, and PL drafted sections 1-2; PL and BT drafted section 4; PES, WTF, and PL drafted sections 5-7. All authors drafted sub-sections relevant to their own expertise, which were then edited and synthesized into sections 3-4 by PES, PL, BT, WTF, and AS. All authors edited and approved the final manuscript.

\section{Conflicts of interest}

None. 


\section{References:}

Alaux, C., Maisonnasse, A., \& Le Conte, Y. (2010). Pheromones in a superorganism: From gene to social regulation. Vitamins \& Hormones 83: 401-23.

Anderson, B. R. O. (1991). Imagined communities: Reflections on the origin and spread of nationalism. New York: Verso.

Arbib, M. A. (2005). "From monkey-like action recognition to human language: An evolutionary framework for neurolinguistics," Behavioral and Brain Sciences 28: 105-67.

Arom, S. (1991). African polyphony and polyrhythm: Musical structure and methodology. Cambridge: Cambridge University Press.

Atwood, S., Schachner, A., \& Mehr, S. A. (2020). Expectancy effects threaten the inferential validity of synchrony-prosociality research. PsyArXiv preprint. https://doi.org/10.31234/osf.io/zjy8u

Atzil, S., Touroutoglou, A., Rudy, T., Salcedo, S., Feldman, R., Hooker, J. M., ... \& Barrett, L. F. (2017). Dopamine in the medial amygdala network mediates human bonding. Proceedings of the National Academy of Sciences USA 114(9): 2361-66.

Atzil, S., Gao, W., Fradkin, I., \& Barrett, L. F. (2018). Growing a social brain. Nature Human Behaviour 2(9): 624-36.

Baldwin, J. M. (1896). A new factor in evolution. The American Naturalist 30(354): 441-51.

Balsby, T. J. S., \& Scarl, J. C. (2008). Sex-specific responses to vocal convergence and divergence of contact calls in orange-fronted conures (Aratinga canicularis). Proceedings of the Royal Society B: Biological Sciences 275: 2147-54.

Bateson, P. (2004). The active role of behaviour in evolution. Biology and Philosophy 19: 283-98.

Bartels, A., \& Zeki, S. (2004). The neural correlates of maternal and romantic love. Neuroimage 21(3): 115566.

Beadle, J. N., Paradiso, S., \& Tranel, D. (2018). Ventromedial prefrontal cortex is critical for helping others who are suffering. Frontiers in Neurology 9: article 288. http://doi.org/10.3389/fneur.2018.00288

Beery, A. K. (2015). Antisocial oxytocin: Complex effects on social behavior. Current Opinion in Behavioral Sciences, 6: 174-182. https://doi.org/10.1016/j.cobeha.2015.11.006

Belfi, A. M., \& Loui, P. (2020). Musical anhedonia and rewards of music listening: current advances and a proposed model. Annals of the New York Academy of Sciences, 1464: 99-114.

Benzon, W. (2001). Beethoven's anvil, music in mind and culture. Berme: Basic Books.

Bergman, T. J. (2013). Speech-like vocalized lip-smacking in geladas. Current Biology 23: 268-9.

Bergman, T. J., \& Beehner, J. C. (2015). Measuring social complexity. Animal Behaviour 103: 203-9.

Bernatzky, G., Presch, M., Anderson, M., \& Panksepp, J. (2011). Emotional foundations of music as a nonpharmacological pain management tool in modern medicine. Neuroscience \& Biobehavioral Reviews 35(9): 1989-99.

Bigler, R. S., Jones, L. C., \& Lobliner, D. B. (1997). Social categorization and the formation of intergroup attitudes in children. Child Development, 68(3): 530-43.

Blood, A. J., \& Zatorre, R. J. (2001). Intensely pleasurable responses to music correlate with activity in brain regions implicated in reward and emotion. Proceedings of the National Academy of Sciences USA 98(20): 11818-23.

Blood, A. J., Zatorre, R. J., Bermudez, P., \& Evans, A. C. (1999). Emotional responses to pleasant and unpleasant music correlate with activity in paralimbic brain regions. Nature Neuroscience 2(4): 38287.

Bloom, P. (2002). How children learn the meanings of words. MIT press.

Bowling, D. L., \& Purves, D. (2015). A biological rationale for musical consonance. Proceedings of the National Academy of Sciences USA 112(36): 11155-60. 
Bowling, D. L., Purves, D., \& Gill, K. Z. (2018). Vocal similarity predicts the relative attraction of musical chords. Proceedings of the National Academy of Sciences USA 115(1): 216-21.

Bowling, D. L., Hoeschele, M., Gill, K. Z., \& Fitch, W. T. (2017). The nature and nurture of musical consonance. Music Perception, 35(1), 118-121.

Boyd, R., \& Richerson, P. J. (1985). Culture and the evolutionary process. Chicago: University of Chicago Press.

Bradbury, J. (2001). Vocal communication of wild parrots. Journal of the Acoustical Society of America. 115: 2373.

Brown, Danielle (2020, June 12). An open letter on racism in music studies: Especially ethnomusicology and music education. My People Tell Stories. https://www.mypeopletellstories.com/blog/open-letter

Brown, Donald E. (1991). Human universals. Philadelphia: Temple University Press.

Brown, S. (2000a). Evolutionary models of music: From sexual selection to group selection. In F. Tonneau \& N. S. Thompson (Eds.), Perspectives in ethology, vol. 13: Evolution, culture, and behavior (Vol. 13, pp. 231-281). New York: Plenum Publishers.

Brown, S. (2000b). The "musilanguage" model of musical evolution. In N. L. Wallin, B. Merker, \& S. Brown (Eds.), The origins of music (pp. 271-300). Cambridge: MIT Press.

Brown, S. (2007). Contagious heterophony: A new theory about the origins of music. Musicae Scientiae, 11(1): 3-26.

Brown, S., \& Jordania, J. (2013). Universals in the world's musics. Psychology of Music 41(2): 229-48.

Brown, S., \& Volgsten, U. (2006). Music and manipulation: On the social uses and social control of music. New York: Berghahn Books.

Cavalli-Sforza, L. L., \& Feldman, M. W. (1981). Cultural transmission and evolution: A quantitative approach. Princeton: Princeton University Press.

Chanda, M. L., \& Levitin, D. J. (2013). The neurochemistry of music. Trends in Cognitive Sciences 17(4): 179-93.

Cheung, V. K. M., Harrison, P. M. C., Meyer, L., Pearce, M. T., Haynes, J.-D., \& Koelsch, S. (2019). Uncertainty and surprise jointly predict musical pleasure and amygdala, hippocampus, and auditory cortex activity. Current Biology, 29(23): 4084-92.

Cirelli, L. K., Einarson, K. M., \& Trainor, L. J. (2014). Interpersonal synchrony increases prosocial behavior in infants. Developmental Science 17(6): 1003-11.

Cirelli, L. K., \& Trehub, S. E. (2018). Infants help singers of familiar songs. Music \& Science, 1: 205920431876162. https://doi.org/10.1177/2059204318761622

Cirelli, L. K., Trehub, S. E., \& Trainor, L. J. (2018). Rhythm and melody as social signals for infants. Annals of the New York Academy of Sciences, 1423(1), 66-72.

Cirelli, L. K., \& Trehub, S. E. (2020). Familiar songs reduce infant distress. Developmental Psychology, 56(5), 861-868.

Cirelli, L. K., Jurewicz, Z. B., \& Trehub, S. E. (2019). Effects of maternal singing style on mother-infant arousal and behavior. Journal of Cognitive Neuroscience. 32(19): 1213-1220

Clark, A. (2013). Whatever next? Predictive brains, situated agents, and the future of cognitive science. Behavioral and Brain Sciences, 36(3): 181-253.

Conard, N. J., Malina, M., \& Münzel, S. C. (2009). New flutes document the earliest musical tradition in southwestern Germany. Nature 460(7256): 737-40.

Cooper, R., \& Aslin, R. (1990). Preference for infant-directed speech in the first month after birth. Child Development 61(5): 1584-95.

Corbeil, M., Trehub, S. E., \& Peretz, I. (2016). Singing delays the onset of infant distress. Infancy 21(3): 373-91.

Cross, I., \& Morley, I. (2009). The evolution of music: Theories, definitions, and the nature of the evidence. In S. Malloch \& C. Trevarthen (Eds.), Communicative musicality: Exploring the basis of human companionship (pp. 61-82). Oxford University Press. 
Cross, E. S., Kraemer, D. J., Hamilton, A. F. D. C., Kelley, W. M., \& Grafton, S. T. (2008). Sensitivity of the action observation network to physical and observational learning. Cerebral Cortex 19(2): 315-26.

Darwin, C. (1871). The descent of man, and selection in relation to sex. London: John Murray.

Davila Ross, M., Owren, M. J., \& Zimmerman, E. (2009). Reconstructing the evolution of laughter in great apes and humans. Current Biology 19: 1106-11.

Declerck, C. H., Boone, C., Pauwels, L., Vogt, B., \& Fehr, E. (2020). A registered replication study on oxytocin and trust. Nature Human Behaviour. https://doi.org/10.1038/s41562-020-0878-X

Decety, J., Jackson, P. L., Sommerville, J. A., Chaminade, T., \& Meltzoff, A. N. (2004). The neural bases of cooperation and competition: An fMRI investigation. Neuroimage 23(2): 744-51.

De Dreu, C.K.W., \& Kret, M.E. (2016) Oxytocin conditions intergroup relations through upregulated ingroup empath, cooperation, conformity, and defense. Biological Psychiatry. 79(3):165-73.

Dengler-Crish, C. M., and Catania, K. C. (2007). Phenotypic plasticity in female naked mole-rats after removal from reproductive suppression. Journal of Experimental Biology 210: 4351-58.

DeNora, T. (2000). Music in everyday life. Cambridge University Press.

Deutsch, D., Henthorn, T., and Lapidis, R. (2011). Illusory transformation from speech to song. Journal of the Acoustical Society of America 129: 2245-52.

Dissanayake, E. (2000). Antecedents of the temporal arts in early mother-infant interaction. In N. L. Wallin, B. Merker, \& S. Brown (Eds.), The origins of music (pp. 389-410). Cambridge, MA: MIT Press.

Dissanayake, E. (2009). Root, leaf, blossom, or bole: Concerning the origin and adaptive function of music. In S. Malloch, \& C. Trevarthen (Eds.), Communicative musicality: Exploring the basis of human companionship (pp. 17-30). Oxford: Oxford University Press

Dölen, G., Darvishzadeh, A., Huang, K. W., \& Malenka, R. C. (2013). Social reward requires coordinated activity of nucleus accumbens oxytocin and serotonin. Nature 501(7466): 179-84 .

Domes, G., Heinrichs, M., Michel, A., Berger, C., \& Herpertz, S. C. (2007). Oxytocin improves "mindreading" in humans. Biological Psychiatry 61(6): 731-33.

Dunbar, R. I. M. (1991). Functional significance of social grooming in primates. Folia Primatologica 57 : $121-31$

Dunbar, R. I. M. (1993). Coevolution of neocortical size, group size and language in humans. Behavioral and Brain Sciences 16: 681-735.

Dunbar, R. I. M. (2012a). On the evolutionary function of song and dance. In N. Bannan (Ed.), Music, language, and human evolution (pp. 201-214). Oxford: Oxford University Press.

Dunbar, R. I. M., (2012b) Bridging the bonding gap: The transition from primates to humans. Philosophical Transactions of the Royal Society B: Biological Science 367(1597): 1837-46.

Dunbar, R. I. M., \& Shultz, S. (2010). Bondedness and sociality. Behaviour, 147(7): 775-803.

Durham, W. H. (1991). Coevolution: Genes, culture, and human diversity. Stanford, CA: University of California Press.

Erber, R., Wegner, D. M., \& Therriault, N. (1996). On being cool and collected: Mood regulation in anticipation of social interaction. Journal of Personality and Social Psychology 70(4): 757-66.

Evans, N., \& Levinson, S. C. (2009). The myth of language universals: Language diversity and its importance for cognitive science. Behavioral and Brain Sciences 32(5): 429-92.

Ewell, P. A. (2020). Music theory and the white racial frame. Music Theory Online, 26(2). https://doi.org/10.30535/mto.26.2.4

Falk, D. (2004). Prelinguistic evolution in early hominins: Whence motherese? Behavioral and Brain Sciences 27(4): 491-541.

Farabaugh, S. M. (1982). The ecological and social significance of duetting. In D. S. Kroodsma \& E. H. Miller (Eds.), Acoustic Communication in Birds, Volume 2 (pp. 85-124). New York, NY: Academic Press.

Fazenda, B., Scarre, C., Till, R., Pasalodos, R.J., Guerra, M.R. Tejedor, C., Peredo, R.O., Watson, A. Wyatt, S., Benito, C.G., Drinkall, H., \& Foulds, F. (2017). Cave acoustics in prehistory: exploring the 
association of Palaeolithic visual motifs and acoustic response. The Journal of the Acoustic Society of America 142, 1332-49.

Feekes, F. (1982). Song mimesis within colonies of Cacicus c. cela (Icteridae: Aves): A colonial password? Zeitschrift Tierpsychology 58: 119-52.

Fernald, A. (1989). Intonation and communicative intent in mothers' speech to infants: Is the melody the message? Child development 60(6): 1497-510.

Fernald, A. (1992). Human maternal vocalizations to infants as biologically relevant signals: An evolutionary perspective. In J. H. Barkow, L. Cosmides, \& J. Tooby (Eds.), The adapted mind: Evolutionary psychology and the generation of culture (pp. 391-428). Oxford University Press.

Finlay, B. L., Darlington, R. B., \& Nicastro, N. (2001). Developmental structure in brain evolution. Behavioral and Brain Sciences 24: 263-308.

Fitch, W. T. (2004). Evolving honest communication systems: Kin selection and "mother tongues". In D. K. Oller \& U. Griebel (Eds.), Evolution of Communication Systems: A Comparative Approach (pp. 275296). Cambridge, MA: MIT Press.

Fitch, W. T. (2006). The biology and evolution of music: A comparative perspective. Cognition 100(1): 173215.

Fitch, W. T. (2010). The evolution of language. Cambridge: Cambridge University Press.

Fitch, W. T. (2015a). Four principles of bio-musicology. Philosophical Transactions of the Royal Society B: Biological Sciences 370(1664): e2014.0091. http://doi.org/10.1098/rstb.2014.0091

Fitch, W. T. (2015b). The biology and evolution of musical rhythm: An update. In I. Toivonen, P. Csúri, \& E. van der Zee (Eds.), Structures in the Mind: Essays on Language, Music, and Cognition in Honor of Ray Jackendoff (pp. 293-324). Cambridge, Massachusetts: MIT Press.

Fitch, W. T. (2017). Empirical approaches to the study of language evolution. Psychonomic Bulletin \& Review 24: 3-33.

Fitch, W. T., von Graevenitz, A., and Nicolas, E. (2009). Bio-aesthetics and the aesthetic trajectory: A dynamic cognitive and cultural perspective. In M. Skov \& O. Vartanian (Eds.), Neuroaesthetics, (pp. 59-102). Amityville, NY: Baywood.

Fitch, W. T., \& Jarvis, E. D. (2013). Birdsong and other animal models for human speech, song, and vocal learning. In M. A. Arbib (Ed.), Language, Music, and the Brain: A Mysterious Relationship (pp. 499539). Cambridge, Massachusetts: MIT Press.

Fletcher, P. T., Whitaker, R. T., Tao, R., DuBray, M. B., Froehlich, A., Ravichandran, C., ... Lainhart, J. E. (2010). Microstructural connectivity of the arcuate fasciculus in adolescents with high-functioning autism. NeuroImage 51(3): 1117-25.

Freeman, W. (2000). A neurobiological role for music in social bonding. In N. L. Wallin, B. Merker, \& S. Brown (Eds.), The Origins of Music (pp. 411-24). Cambridge, MA: MIT Press.

Frigyesi, J. (1993). Preliminary thoughts toward the study of music without clear beat: The example of "Flowing Rhythm" in Jewish "Nusah". Asian Music 24: 59-88.

Friston, K. (2010). The free-energy principle: A unified brain theory? Nature Reviews Neuroscience 11: 12737.

Fujii, T., Schug, J., Nishina, K., Takahashi, T., \& Okada, H. (2016). Relationship between salivary oxytocin levels and generosity in preschoolers. Scientific Reports 6(38662):1-7.

Fujioka, T., Ross, B., \& Trainor, L. J. (2015). Beta-band oscillations represent auditory beat and its metrical hierarchy in perception and imagery. Journal of Neuroscience 35(45): 15187-98.

Gadagkar, V., Puzerey, P. A., Chen, R., Baird-Daniel, E., Farhang, A. R., \& Goldberg, J. H. (2016). Dopamine neurons encode performance error in singing birds. Science 354(6317): 1278-82.

Gamble. C. (2010). Technologies of separation and the evolution of social extension. In Social Brain, Distributed Mind (Eds, Dunbar, R,.., Gamble, C. \& Gowlett, J), pp. 17-42. Oxford: Oxford University Press. 
Gebauer, L., Witek, M. A. G., Hansen, N. C., Thomas, J., Konvalinka, I., \& Vuust, P. (2016). Oxytocin improves synchronisation in leader-follower interaction. Scientific Reports, 6, 38416.

https://doi.org/10.1038/srep38416

Geissmann, T. (1999). Duet songs of the siamang, Hylobates syndactylus: II. Testing the pair-bonding hypothesis during a partner exchange. Behaviour 136(8): 1005-39.

Gelfand, M. J., Caluori, N., Jackson, J. C., \& Taylor, M. K. (2020). The cultural evolutionary trade-off of ritualistic synchrony. Philosophical Transactions of the Royal Society B: Biological Sciences, 375: 20190432. https://doi.org/10.1098/rstb.2019.0432

Geschwind, N. (1965). Disconnexion syndromes in animal and man. Brain 88: 585-644.

Ghazban, N. (2013). Emotion regulation in infants using maternal singing and speech. $\mathrm{PhD}$ dissertation, Ryerson University, Toronto.

Gil, D., \& Gahr, M. (2002). The honesty of bird song: Multiple constraints for multiple traits. Trends in Ecology \& Evolution 17(3): 133-41.

Gill, K. Z., \& Purves, D. (2009). A biological rationale for musical scales. PLOS ONE 4(12): e8144. https://doi.org/10.1371/journal.pone.0008144

Gingras, B., Honing, H., Peretz, I., Trainor, L. J., \& Fisher, S. E. (2018). Defining the biological bases of individual differences in musicality. In H. Honing (Ed.), The origins of musicality (pp. 221-250). Cambridge, MA: MIT Press.

Gioia, T. (2019). Music: A subversive history. New York: Basic Books.

Good, A., \& Russo, F. A. (2016). Singing promotes cooperation in a diverse group of children. Social Psychology, 47(6): 340-344.

Gold, B. P., Mas-Herrero, E., Zeighami, Y., Benovoy, M., Dagher, A., \& Zatorre, R. J. (2019). Musical reward prediction errors engage the nucleus accumbens and motivate learning. Proceedings of the National Academy of Sciences USA 116(8): 3310-15.

Grahn, J. A., \& Brett, M. (2007). Rhythm and beat perception in motor areas of the brain. Journal of Cognitive Neuroscience 19(5): 893-906.

Grahn, J. A., \& Rowe, J. B. (2009). Feeling the beat: Premotor and striatal interactions in musicians and nonmusicians during beat perception. Journal of Neuroscience 29(23): 7540-48.

Grahn, J., Bauer, A.-K. R., \& Zamm, A. (2020, April 28). Music-making brings us together during the coronavirus pandemic. The Conversation. https://theconversation.com/music-making-brings-ustogether-during-the-coronavirus-pandemic-137147

Grape, C., Sandgren, M., Hansson, L.-O., Ericson, M., \& Theorell, T. (2003). Does singing promote wellbeing?: An empirical study of professional and amateur singers during a singing lesson. Integrative Physiological \& Behavioral Science 38(1): 65-74.

Grawunder, S., Crockford, C., Clay, Z., Kalan, A. K., Stevens, J. M. G., Stoessel, A., \& Hohmann, G. (2018). Higher fundamental frequency in bonobos is explained by larynx morphology. Current Biology 28(20): R1188-89.

Greenwood, D. N., \& Long, C. R. (2009). Mood specific media use and emotion regulation: Patterns and individual differences. Personality and Individual Differences 46(5-6): 616-621.

Griffiths, P. E. (2003). Beyond the Baldwin effect: James Mark Baldwin's "social heredity", epigenetic inheritance, and niche construction. In B. Weber \& D. J. Depew (Eds.), Learning, Meaning and Emergence: Possible Baldwinian Mechanisms in the Co-Evolution of Mind and Language (pp. 193215). Cambridge, MA: MIT Press.

Gustison, M. L., Aliza, L. R., and Bergman, T. (2012). Derived vocalizations of geladas (Theropithecus gelada) and the evolution of vocal complexity in primates. Philosophical Transactions of the Royal Society B: Biological Sciences 367: 1847-59.

Hagen, E. H., \& Bryant, G. A. (2003). Music and dance as a coalition signaling system. Human Nature 14(1): 21-51. 
Haimoff, E. H. (1986). Convergence in the duetting of monogamous Old World primates. Journal of Human Evolution 15: 51-59.

Hall, M. L. (2004). A review of hypotheses for the functions of avian duetting. Behavioral Ecology and Sociobiology 55: 415-430.

Halwani, G. F., Loui, P., Rüber, T., \& Schlaug, G. (2011). Effects of practice and experience on the arcuate fasciculus: Comparing singers, instrumentalists, and non-musicians. Frontiers in Psychology 2: article 156. http://doi.org/10.3389/fpsyg.2011.00156

Hanslick, E. (1858). Vom Musikalisch-Schönen. Leipzig: Ruoldf Weigel.

Harrison, P. M. C., \& Pearce, M. T. (2020). Simultaneous consonance in music perception and composition. Psychological Review. 127(2): 216-244.

Henrich, J. (2016). The secret of our success: How culture is driving human evolution, domesticating our species, and making us smarter. Princeton, NJ: Princeton University Press.

Hoeschele, M., Merchant, H., Kikuchi, Y., Hattori, Y., \& ten Cate, C. (2018). Searching for the origins of musicality across species. In H. Honing (Ed.), The origins of musicality (pp. 149-170). Cambridge, MA: MIT Press.

Honing, H., Cate, C., Peretz, I., \& Trehub, S. E. (2015). Without it no music: Cognition, biology and evolution of musicality. Philosophical Transactions of the Royal Society B: Biological Sciences 370: 20140088. http://doi.org/10.1098/rstb.2014.0088

Honing, H. (Ed.). (2018). The origins of musicality. Cambridge, MA: MIT Press.

Horowitz, J. (2020, March 14). Italians find 'a moment of joy in this moment of anxiety'. New York Times. https://www.nytimes.com/2020/03/14/world/europe/italians-find-a-moment-of-joy-in-this-moment-ofanxiety.html

Hove, M. J., \& Risen, J. L. (2009). It's all in the timing: Interpersonal synchrony increases affiliation. Social Cognition 27(6): 949-60.

Hrdy SB. (2009) Mothers and others: The evolutionary origins of mutual understanding. Cambridge, MA: Harvard University Press.

Hurlemann, R., Patin, A., Onur, O.A., Cohen, M.X., Baumgartner, T., Metzler, S.,.., Kendrick, K.M. (2010). Oxytocin enhances amygdala-dependent, socially reinforced learning and emotional empathy in humans. Journal of Neuroscience 30:4999-5007.

Huron, D. (2001). Is music an evolutionary adaptation? Annals of the New York Academy of Sciences 930: 43-61.

Huron, D. (2006). Sweet anticipation: Music and the psychology of expectation. MIT Press.

Inagaki, T.K. (2018). Opioids and social connection. Current Directions in Psychological Science, 27: 8590.

Inagaki, T.K., Ray, L.A., Irwin, M.R., Way, B.M., \& Eisenberger, N.I. (2016). Opioids and social bonding: naltrexone reduces feelings of social connection. Social Cognitive and Affective Neuroscience 11: 728 35.

Iyer, V., \& Born, G. (2020, February 18). Of musicalities and musical experience: Vijay Iyer and Georgina Born in conversation. Wigmore Hall Podcasts. https://wigmore-hall.org.uk/podcasts/of-musicalitiesand-musical-experience-vijay-iyer-and-georgina-born-in-conversation

Jablonka, E., Ginsburg, S., \& Dor, D. (2012). The co-evolution of language and emotions. Philosophical Transactions of the Royal Society B: Biological Sciences, 367(1599): 2152-2159.

Jablonka, E., \& Lamb, M. J. (2005). Evolution in four dimensions: Genetic, epigenetic, behavioral, and symbolic variation in the history of life. MIT Press.

Jackson, S. J., \& Hokowhitu, B. (2002). Sport, tribes, and technology: The New Zealand All Blacks haka and the politics of identity. Journal of Sport \& Social Issues, 26(2): 125-39.

Jacoby, N., Margulis, E., Clayton, M., Hannon, E., Honing, H., Iversen, J.,..., Wald-Fuhrmann, M. (2020). Cross-cultural work in music cognition: Methodologies, pitfalls, and practices. Music Perception, 37(3): 185-195. 
Jacoby, N., \& McDermott, J. H. (2017). Integer ratio priors on musical rhythm revealed cross-culturally by iterated reproduction. Current Biology 27: 359-70.

Jacoby, N., Undurraga, E. A., McPherson, M. J., Valdés, J., Ossandón, T., \& McDermott, J. H. (2019). Universal and non-universal features of musical pitch perception revealed by singing. Current Biology, 29, 3229-43.

Jacoby, N., et al. (In prep.). A global survey of rhythm representations.

Janata, P., Tomic, S. T., \& Haberman, J. M. (2012). Sensorimotor coupling in music and the psychology of the groove. Journal of Experimental Psychology 141(1): 54-75.

Janik, V. M., \& Slater, P. J. B. (1999). Vocal learning in mammals. Advances in the Study of Behavior 26: 59-99.

Järvinen-Pasley, A., Vines, B. W., Hill, K. J., Yam, A., Grichanik, M., Mills, D.,.., Bellugi, U. (2010). Cross-modal influences of affect across social and non-social domains in individuals with Williams syndrome. Neuropsychologia, 48(2): 456-466.

Jarvis, E. D. (2019). Evolution of vocal learning and spoken language. Science, 366: 50-54.

Jones, M. R. (2018). Time will tell: A theory of dynamic attending. Oxford University Press.

Josef, L., Goldstein, P., Mayseless, N., Ayalon, L., \& Shamay-tsoory, S.G. (2019). The oxytocinergic system mediates synchronized interpersonal movement during dance. Scientific Reports 9(1894):1-8.

Keeler, J. R., Roth, E. A., Neuser, B. L., Spitsbergen, J. M., Waters, D. J. M., \& Vianney, J.-M. (2015). The neurochemistry and social flow of singing: Bonding and oxytocin. Frontiers in Human Neuroscience 9 : article 518. https://doi.org/10.3389/fnhum.2015.00518

Keverne, E. B., Martensz, N. D. \& Tuite, B. (1989). Beta-endorphin concentrations in cerebrospinal fluid of monkeys are influenced by grooming relationships. Psychoneuroendocrinology 14: 155-61.

Kim, M., \& Schachner, A. (2020). The origins of dance: Characterizing the development of infants' earliest dance behavior. Poster presented at the Brain Cognition Emotion Music Conference. https://osf.io/meetings/BCEM/.

Kirby, S. (2017). Culture and biology in the origins of linguistic structure. Psychonomic Bulletin \& Review, 24: 118-137.

Kirschner, S., \& Tomasello, M. (2010). Joint music making promotes prosocial behavior in 4-year-old children. Evolution and Human Behavior 31(5): 354-64.

Knutson, B., Westdorp, A., Kaiser, E., \& Hommer, D. (2000). fMRI visualization of brain activity during a monetary incentive delay task. Neuroimage 12(1): 20-27.

Koelsch, S., Vuust, P., \& Friston, K. (2019). Predictive processes and the peculiar case of music. Trends in Cognitive Sciences, 23(1), 63-77.

Kokal, I., Engel, A., Kirschner, S., \& Keysers, C. (2011). Synchronized drumming enhances activity in the caudate and facilitates prosocial commitment - if the rhythm comes easily. PLOS ONE 6(11): e27272. http://doi.org/10.1371/journal.pone.0027272

Kornhaber, S. (2020, April 9). The coronavirus has forced a repurposing of music. The Atlantic. https://www.theatlantic.com/culture/archive/2020/04/coronavirus-has-forced-repurposingmusic/609601/

Kosfeld, M., Heinrichs, M., Zak, P., Fischbacher, U., \& Fehr, E. (2005). Oxytocin increases trust in humans. Nature 435(7042): 673-76.

Kroodsma, D. E. (1978). Continuity and versatility in bird song: Support for the monotony-threshold hypothesis. Nature, 274(5672), 681-3.

Kuroyanagi, J., Sato, S., Ho, M.-J., Chiba, G., Six, J., Pfordresher, P., ... Savage, P. E. (2019). Automatic comparison of human music, speech, and bird song suggests uniqueness of human scales. In Proceedings of the 9th International Workshop on Folk Music Analysis (FMA2019), pp. 35-40. http://doi.org/10.31234/osf.io/zpv5w

Lagacé, R. O. (1979). The HRAF Probability Sample: Retrospect and prospect. Cross-Cultural Research, 14(3), 211-29. 
Lakens, D., \& Stel, M. (2011). If they move in sync, they must feel in sync: Movement synchrony leads to attributions of rapport and entitativity. Social Cognition 29(1): 1-14.

Laland, K. N., \& Brown, G. R. (2011). Sense and nonsense: Evolutionary perspectives on human behaviour (2nd ed.). Oxford University Press.

Laland, K. N., Odling-Smee, J., \& Feldman, M. W. (2000). Niche construction, biological evolution, and cultural change. Behavioral and Brain Sciences 23: 131-75.

Laland, K. N., Odling-Smee, J., \& Myles, S. (2010). How culture shaped the human genome: Bringing genetics and the human sciences together. Nature Reviews Genetics 11: 137-48.

Laland, K., Wilkins, C., \& Clayton, N. (2016). The evolution of dance. Current Biology 26(1): R5-9.

Lang, M., Bahna, V., Shaver, J. H., Reddish, P., \& Xygalatas, D. (2017). Sync to link: Endorphin-mediated synchrony effects on cooperation. Biological Psychology, 127: 191-197.

Large, E. W., Kim, J. C., Flaig, N. K., Bharucha, J., \& Krumhansl, C. L. (2016). A neurodynamic account of musical tonality. Music Perception, 33(3), 319-31.

Launay, J., Dean, R. T., \& Bailes, F. (2013). Synchronization can influence trust following virtual interaction. Experimental Psychology 60(1): 53-63.

Launay, J., Tarr, B., \& Dunbar, R. I. M. (2016). Synchrony as an adaptive mechanism for large-scale human social bonding. Ethology 122: 779-89.

Le Merrer, J., Becker, J. A., Befort, K., \& Kieffer, B. L. (2009). Reward processing by the opioid system in the brain. Physiological reviews 89(4): 1379-1412.

Lense, M. D., Gordon, R. L., Key, A. P. F., \& Dykens, E. M. (2014). Neural correlates of cross-modal affective priming by music in Williams syndrome. Social Cognitive and Affective Neuroscience, 9(4), 529-537.

Lepage, C., Drolet, P., Girard, M., Grenier, Y., \& DeGagné, R. (2001). Music decreases sedative requirements during spinal anesthesia. Anesthesia \& Analgesia 93(4): 912-16.

Lomax, A. (Ed.). (1968). Folk song style and culture. Washington, DC: American Association for the Advancement of Science.

London, J. (2004). Hearing in time: Psychological aspects of musical meter. Oxford: Oxford University Press.

Longfellow, H. W. (1835). A pilgrimage beyond the sea. New York: Harper \& Bros.

Loersch, C., \& Arbuckle, N. L. (2013). Unraveling the mystery of music: Music as an evolved group process. Journal of Personality and Social Psychology 105(5): 777-98.

Loui, P., Alsop, D., \& Schlaug, G. (2009). Tone deafness: A new disconnection syndrome? The Journal of Neuroscience 29(33): 10215-20.

Loui, P., Li, H. C., \& Schlaug, G. (2011). White matter integrity in right hemisphere predicts pitch-related grammar learning. NeuroImage 55(2): 500-07.

Loui, P., Patterson, S., Sachs, M. E., Leung, Y., Zeng, T., \& Przysinda, E. (2017). White matter correlates of musical anhedonia: Implications for evolution of music. Frontiers in Psychology 8: article 1664. http://doi.org/10.3389/fpsyg.2017.01664

Love, T. M. (2014). Oxytocin, motivation and the role of dopamine. Pharmacology Biochemistry and Behavior 119: 49-60.

Maestripieri, D. (2010). Neurobiology of social behavior. In M. Platt \& A. Ghazanfar (Eds.), Primate Neuroethology (pp. 359-384). Oxford: Oxford University Press.

Mann, N. I., Dingess, K. A., Barker, K., Graves, J. A., \& Slater, P. J. B. (2009). A comparative study of song form and duetting in neotropical Thryothorus wrens. Behaviour 146: 1-43.

Mann, N. I., Dingess, K. A., and Slater, P. J. B. (2006). Antiphonal four-part synchronized chorusing in a Neotropical wren. Biology Letters 2: 1-4.

ManyBabies Consortium (2020). Quantifying sources of variability in infancy research using the infantdirected speech preference. Advances in Methods and Practices in Psychological Science, 3(1): 24-52.

Margulis, E. H. (2014). On repeat: How music plays the mind. New York: Oxford University Press. 
Martínez-Molina, N., Mas-Herrero, E., Rodríguez-Fornells, A., Zatorre, R. J., \& Marco-Pallarés, J. (2016). Neural correlates of specific musical anhedonia. Proceedings of the National Academy of Sciences USA 113(46): E7337-45.

Mas-Herrero, E., Zatorre, R. J., Rodriguez-Fornells, A., \& Marco-Pallarés, J. (2014). Dissociation between musical and monetary reward responses in specific musical anhedonia. Current Biology 24(6): 699704.

McAuley, J. D., Jones, M. R., Holub, S., Johnston, H. M., \& Miller, N. S. (2006). The time of our lives: Life span development of timing and event tracking. Journal of Experimental Psychology: General, 135(3): 348-367.

McBride, J. M., \& Tlusty, T. (2020). Cross-cultural data shows musical scales evolved to maximise imperfect fifths. ArXiv Preprint. http://arxiv.org/abs/1906.06171

McDermott, J. H., Lehr, A. J., \& Oxenham, A. J. (2010). Individual differences reveal the basis of consonance. Current Biology 20(11): 1035-1041.

McDermott, J. H., Schultz, A. F., Undurraga, E. A., \& Godoy, R. A. (2016). Indifference to dissonance in native Amazonians reveals cultural variation in music perception. Nature, 535: 547-550.

McNeil, W. H. (1995). Keeping together in time: Dance and drill in human history. Cambridge, MA: Harvard University Press.

Mehr, S. A., \& Krasnow, M. M. (2017). Parent-offspring conflict and the evolution of infant-directed song. Evolution and Human Behavior 38: 674-84.

Mehr, S. A., Krasnow, M. M., Bryant, G. A., \& Hagen, E. H. (This issue). Origins of music in credible signaling. Behavioral and Brain Sciences. Preprint: https://doi.org/10.31234/osf.io/nrqb3

Mehr, S. A., Singh, M., York, H., Glowacki, L., \& Krasnow, M. M. (2018). Form and function in human song. Current Biology 28: 356-368.

Mehr, S. A., Singh, M., Knox, D., Lucas, C., Ketter, D. M., Pickens-Jones, D., ... Glowacki, L. (2019). Universality and diversity in human song. Science, 366: eaax0868. https://doi.org/10.1126/science.aax0868

Mehr, S. A., Song, L. A., \& Spelke, E. S. (2016). For 5-month-old infants, melodies are social. Psychological Science 27(4): 486-501.

Mercado, E., Mantell, J. T., \& Pfordresher, P. Q. (2014). Imitating sounds: A cognitive approach to understanding vocal imitation. Comparative Cognition \& Behavior Reviews, 9: 17-74.

Merchant, H., Grahn, J., Trainor, L., Rohrmeier, M., \& Fitch, W. T. (2015). Finding the beat: A neural perspective across humans and non-human primates. Philosophical Transactions of the Royal Society B: Biological Sciences 370: 20140093. http://doi.org/10.1098/rstb.2014.0093

Merker, B. (1999). Synchronous chorusing and the origins of music. Musicae Scientiae 3: 59-73.

Merker, B. (2000). Synchronous chorusing and human origins. In The origins of music (pp. 315-328). Cambridge, MA: MIT Press.

Merker, B. (2002). Music: The missing Humboldt system. Musicae Scientiae, 6(1), 3-21.

Merker, B. H., Madison, G. S., \& Eckerdal, P. (2009). On the role and origin of isochrony in human rhythmic entrainment. Cortex, 45(1), 4-17.

Merker, B., Morley, I., \& Zuidema, W. (2018). Five fundamental constraints on theories of the origins of music. In H. Honing (Ed.), The origins of musicality (pp. 70-104). MIT Press.

Merriam, A. P. (1964). The anthropology of music. Northwestern University Press.

Miles, L. K., Nind, L. K., \& Macrae, C. N. (2009). The rhythm of rapport: Interpersonal synchrony and social perception. Journal of Experimental Social Psychology 45(3): 585-89.

Miller, G. F. (2000). Evolution of human music through sexual selection. In N. L. Wallin, B. Merker, \& S. Brown (Eds.), The origins of music (pp. 329-360). Cambridge, MA: MIT Press.

Mitchell, J. P., Banaji, M. R., \& Macrae, C. N. (2005). The link between social cognition and self-referential thought in the medial prefrontal cortex. Journal of Cognitive Neuroscience 17(8): 1306-15. 
Mithen, S. J. (2005). The singing Neanderthals: The origins of music, language, mind, and body. London: Weldenfeld \& Nicholson.

Mogan, R., Fischer, R., \& Bulbulia, J. A. (2017). To be in synchrony or not? A meta-analysis of synchrony's effects on behavior, perception, cognition and affect. Journal of Experimental Social Psychology 72: $13-20$.

Moore, E., Schaefer, R. S., Bastin, M. E., Roberts, N., \& Overy, K. (2017). Diffusion tensor MRI tractography reveals increased fractional anisotropy (FA) in arcuate fasciculus following music-cued motor training. Brain and Cognition 116: 40-46.

Morillon, B., \& Baillet, S. (2017). Motor origin of temporal predictions in auditory attention. Proceedings of the National Academy of Sciences USA 114(42): E8913-E8921.

Morley, I. (2013). The prehistory of music: Human evolution, archaeology, and the origins of musicality. Oxford: Oxford University Press.

Mueller, C., Klega, A., Buchholz, H.-G., Rolke, R., Magerl, W., Schirrmacher, R., ... Schreckenberger, M. (2010). Basal opioid receptor binding is associated with differences in sensory perception in healthy human subjects: a [18F]diprenorphine PET study. NeuroImage 49(1): 731-37.

Nakata, T., \& Trehub, S. E. (2004). Infants' responsiveness to maternal speech and singing. Infant Behavior and Development 27(4): 455-64.

Nave, G., Camerer, C., \& McCullough, M. (2015). Does oxytocin increase trust in humans? A critical review of research. Perspectives on Psychological Science, 10(6), 772-89.

Nettl, B. (2015). The study of ethnomusicology: Thirty-three discussions (3rd ed.). Champaign: University of Illinois Press.

Nettl, B., Stone, R., Porter, J., \& Rice, T. (Eds.). (1998-2002). The Garland encyclopedia of world music. New York: Garland Pub.

Niarchou, M., Sathirapongsasuti, J. F., Jacoby, N., Bell, E., McArthur, E., Straub, P., .. Gordon, R. L. (2019). Unravelling the genetic architecture of rhythm. bioRxiv preprint. https://doi.org/10.1101/836197

Nooshin, L. (2011). Introduction to the special issue: The ethnomusicology of Western art music. Ethnomusicology Forum 20(3): 285-300.

North, A. C., Hargreaves, D. J., \& Hargreaves, J. J. (2004). Uses of music in everyday life. Music Perception, 22(1): 41-77.

Notroff, J. Dietrich, O. \& Schmidt, K. (2015). Gathering of the dead? The early Neolithic sanctuaries of Gobekli Tepe, southerneastern Turkey. In Death Rituals, Social Order and the Archaeology of Immortality in the Ancient World (eds. Renfrew, Sc., Boyd, M.J, and Morely, I), pp. 65-18. Cambridge: Cambridge University Press.

Nowicki, S., \& Searcy, W. A. (2014). The evolution of vocal learning. Current Opinion in Neurobiology 28: 48-53.

Oesch, N. (2019). Music and language in social interaction: Synchrony, antiphony, and functional origins. Frontiers in Psychology, 10, 1514. https://doi.org/10.3389/fpsyg.2019.01514

Parkinson, C., \& Wheatley, T. (2014). Relating anatomical and social connectivity: White matter microstructure predicts emotional empathy. Cerebral Cortex 24(3): 614-25.

Patel, A. D. (2008). Music, language and the brain. Oxford: Oxford University Press.

Patel, A. D. (2014). The evolutionary biology of musical rhythm: Was Darwin wrong? PLoS Biology 12(3): e1001821. http://doi.org/10.1371/journal.pbio.1001821

Patel, A. D. (2018). Music as a transformative technology of the mind: An update. In H. Honing (Ed.), The origins of musicality (pp. 113-26). Cambridge, MA: MIT Press.

Patel, A. D., Iversen, J. R., Bregman, M. R., \& Schulz, I. (2009). Experimental evidence for synchronization to a musical beat in a nonhuman animal. Current Biology 19: 827-30.

Pearce, E., Launay, J., \& Dunbar, R. I. M. (2015). The ice-breaker effect: Singing mediates fast social bonding. Royal Society Open Science 2: 150221. http://doi.org/10.1098/rsos.150221 
Peretz, I., \& Coltheart, M. (2003). Modularity of music processing. Nature Neuroscience, 6(7): 688-691.

Peretz, I., Vuvan, D. T., Lagrois, M.-É., \& Armony, J. (2018). Neural overlap in processing music and speech. In H. Honing (Ed.), The origins of musicality (pp. 205-220). Cambridge, MA: MIT Press.

Pfordresher, P. Q., \& Brown, S. (2017). Vocal mistuning reveals the origin of musical scales. Journal of Cognitive Psychology, 29(1): 35-52.

Pinker, S. (1997). How the mind works. New York: Norton.

Pinker, S. (2007). Toward a consilient study of literature. Philosophy and Literature 31(1): 162-78.

Pinker, S. (2012, June 18). The false allure of group selection. Edge. Available at https://www.edge.org/conversation/steven pinker-the-false-allure-of-group-selection

Podlipniak, P. (2017). The role of the Baldwin effect in the evolution of human musicality. Frontiers in Neuroscience, 11(542). https://doi.org/10.3389/fnins.2017.00542

Polak, R., Jacoby, N., Fischinger, T., Goldberg, D., Holzapfel, A., \& London, J. (2018). Rhythmic prototypes across cultures: A comparative study of tapping synchronization. Music Perception 36(1): 1-23.

Prince, J. B., Thompson, W. F., \& Schmuckler, M. A. (2009). Pitch and time, tonality and meter: How do musical dimensions combine? Journal of Experimental Psychology: Human Perception and Performance, 35(5): 1598-1617.

Rabinowitch, T.-C., Cross, I., \& Burnard, P. (2013). Long-term musical group interaction has a positive influence on empathy in children. Psychology of Music, 41(4): 484-498.

Rabinowitch, T. C., \& Meltzoff, A. N. (2017). Synchronized movement experience enhances peer cooperation in preschool children. Journal of Experimental Child Psychology 160: 21-32.

Ragen, B. J., Maninger, N., Mendoza, S. P., Jarcho, M. R., \& Bales, K. L. (2013). Presence of a pair-mate regulates the behavioral and physiological effects of opioid manipulation in the monogamous titi monkey (Callicebus cupreus). Psychoneuroendocrinology 38(11): 2448-61.

Rainio, R., Lahelma, A., Aikas, T., Lassfolk, K. \& Okkonen, J. (2018). Acoustic measurements and digital image processing suggest a link between sound rituals and sacred sites in northern Finland. Journal of Archaeological Method and Theory 25, 453-74.

Ravignani, A., Delgado, T., \& Kirby, S. (2016). Musical evolution in the lab exhibits rhythmic universals. Nature Human Behaviour 1: article 7. http://doi.org/10.1038/s41562-016-0007

Read, D. \& Van der Feeuw, S. (2015). The extension of social relations in time and space during the Palaeolithic and beyond. In Settlement, Society and Cognition in Human Evolution (eds, Coward, F., Hosfield, R., Pope, M. \& Wenban-Smith, F), pp. 31-53. Cambridge: Cambridge University Press

Reddish, P., Bulbulia, J., \& Fischer, R. (2014). Does synchrony promote generalized prosociality? Religion, Brain \& Behavior 4(1): 3-19.

Reddish, P., Fischer, R., \& Bulbulia, J. (2013). Let's dance together: Synchrony, shared intentionality and cooperation. PLOS ONE 8(8): e71182. http://doi.org/10.1371/journal.pone.0071182

Rennung, M., \& Göritz, A. S. (2016). Prosocial consequences of interpersonal synchrony: A meta-analysis. Zeitschrift Für Psychologie 224(3): 168-89.

Rentfrow, P. J., \& Gosling, S. D. (2006). Message in a ballad: The role of music preferences in interpersonal perception. Psychological Science 17(3): 236-242.

Richerson, P., Baldini, R., Bell, A., Demps, K., Frost, K., Hillis, V., ... Zefferman, M. (2016). Cultural group selection plays an essential role in explaining human cooperation: A sketch of the evidence. Behavioral and Brain Sciences 39: e30. http://doi.org/10.1017/S0140525X1400106X

Richerson, P. J., Boyd, R., \& Henrich, J. (2010). Gene-culture coevolution in the age of genomics. Proceedings of the National Academy of Sciences USA 107: 8985-92.

Gustison, M. L., Aliza, L. R., and Bergman, T. (2012). "Derived vocalizations of geladas (Theropithecus gelada) and the evolution of vocal complexity in primates," Philosophical Transactions of the Royal Society of London B, 367: 1847-1859.

Richman, B. (1978). The synchronisation of voices by gelada monkeys. Primates 19: 569-81.

Richman, B. (1987). Rhythm and melody in gelada vocal exchanges. Primates 28: 199-223. 
Rock, A. M. L., Trainor, L. J. D., \& Addison, T. L. (1999). Distinctive messages in infant-directed lullabies and play songs. Developmental Psychology, 35(2): 527-34.

Roederer, J. G. (1984). The search for a survival value of music. Music Perception 1(3): 350-356.

Sachs, C. (1943). The rise of music in the ancient world: East and West. New York: Norton.

Sachs, M. E., Ellis, R. J., Schlaug, G., \& Loui, P. (2016). Brain connectivity reflects human aesthetic responses to music. Social Cognitive and Affective Neuroscience 11(6): 884-91.

Sakata, J. T., \& Brainard, M. S. (2008). Online contributions of auditory feedback to neural activity in avian song control circuitry. Journal of Neuroscience 28(44): 11378-90.

Salimpoor, V. N., Benovoy, M., Larcher, K., Dagher, A., \& Zatorre, R. J. (2011). Anatomically distinct dopamine release during anticipation and experience of peak emotion to music. Nature Neuroscience 14(2): 257-264.

Salimpoor, V. N., van den Bosch, I., Kovacevic, N., McIntosh, A. R., Dagher, A., \& Zatorre, R. J. (2013). Interactions between the nucleus accumbens and auditory cortices predict music reward value. Science 340(6129): 216-219.

Salimpoor, V. N., Zald, D. H., Zatorre, R. J., Dagher, A., \& McIntosh, A. R. (2015). Predictions and the brain: How musical sounds become rewarding. Trends in Cognitive Sciences 19(2): 86-91.

Sammler, D., Grosbras, M. H., Anwander, A., Bestelmeyer, P. E. G., \& Belin, P. (2015). Dorsal and ventral pathways for prosody. Current Biology 25(23): 3079-85.

Sanchez, J.L.J. 2007. Procession and performance: recreating ritual soundscapes among the Ancient Maya. The World of Music 49, 35-44.

Savage, P. E. (2018). Alan Lomax's Cantometrics Project: A comprehensive review. Music \& Science 1. http://doi.org/10.1177/2059204318786084

Savage, P. E. (2019a). Cultural evolution of music. Palgrave Communications 5: article 16. http://doi.org/10.1057/s41599-019-0221-1

Savage, P. E. (2019b). Universals. In J. L. Sturman (Ed.), The SAGE International Encyclopedia of Music and Culture (p. 2282-2285). Thousand Oaks: SAGE Publications.

http://doi.org/10.4135/9781483317731.n759

Savage, P. E. (2019c). An overview of cross-cultural music corpus studies. In D. Shanahan, A. Burgoyne, \& I. Quinn (Eds.), Oxford Handbook of Music and Corpus Studies. New York: Oxford University Press. http://doi.org/10.31235/osf.io/nxtbg

Savage, P. E., \& Brown, S. (2013). Toward a new comparative musicology. Analytical Approaches to World Music 2(2): 148-97.

Savage, P. E., Brown, S., Sakai, E., \& Currie, T. E. (2015). Statistical universals reveal the structures and functions of human music. Proceedings of the National Academy of Sciences USA 112(29): 8987-92.

Savage, P. E., Merritt, E., Rzeszutek, T., \& Brown, S. (2012). CantoCore: A new cross-cultural song classification scheme. Analytical Approaches to World Music, 2(1): 87-137.

Savage, P. E., Yamauchi, M., Hamaguchi, M., Tarr, B., Kitayama, Y., \& Fujii, S. (2020). Rhythm, synchrony, and cooperation [Stage 1 Registered Report]. PsyArXiv preprint. https://doi.org/10.31234/osf.io/46bd9

Scarl, J. C., \& Bradbury, J. W. (2009). Rapid vocal convergence in an Australian cockatoo, the galah. Animal Behaviour 77: 1019-26.

Schachner, A., Brady, T. F., Pepperberg, I. M., \& Hauser, M. D. (2009). Spontaneous motor entrainment to music in multiple vocal mimicking species. Current Biology 19: 831-36.

Schachner, A., \& Hannon, E. E. (2011). Infant-directed speech drives social preferences in 5-month-old infants. Developmental Psychology 47(1): 19-25.

Schachner, A., Brady, T. F., Oro, K., \& Lee, M. (Preprint). Intuitive archeology: Detecting social transmission in the design of artifacts. PsyArXiv preprint: $\underline{\text { https://doi.org/10.31234/osf.io/g6qxh }}$

Schino, G., \& Troisi, A. (1992). Opiate receptor blockade in juvenile macaques: Effect on affiliative interactions with their mothers and group companions. Brain Research 576: 125-30. 
Schulkin, J., \& Raglan, G. B. (2014). The evolution of music and human social capability. Frontiers in Neuroscience 8: article 292. https://doi.org/10.3389/fnins.2014.00292

Schruth, D., Templeton, C. N., \& Holman, D. J. (In press). On reappearance and complexity in musical calling. PLOS ONE. Preprint: https://doi.org/10.1101/649459

Schultz, W., \& Dickinson, A. (2000). Neuronal coding of prediction errors. Annual Review of Neuroscience 23: 473-500.

Schultz, W., Dayan, P., \& Montague, P. R. (1997). A neural substrate of prediction and reward. Science 275(5306): 1593-99.

Sethares, W. (2004). Tuning, timbre, spectrum, scale. Springer-Verlag.

Shamay-Tsoory, S. G., \& Abu-Akel, A. (2016). The social salience hypothesis of oxytocin. Biological Psychiatry 79(3): 194-202.

Shilton, D., Breski, M., Dor, D., \& Jablonka, E. (2020). Human social evolution: Self-domestication or selfcontrol? Frontiers in Psychology, 11(134). https://doi.org/10.3389/fpsyg.2020.00134

Shultz, S., \& Dunbar, R. I. M. (2007). The evolution of the social brain: Anthropoid primates contrast with other vertebrates. Proceedings of the Royal Society B: Biological Sciences 274: 2429-36.

Shultz, S., Opie, C., \& Atkinson, Q. D. (2011). Stepwise evolution of stable sociality in primates. Nature, 479(7372): 219-222.

Silk, J. B. (2007). Social components of fitness in primate groups. Science 317: 1347-1351.

Sloboda, J. A., O'Neill, S. A., \& Ivaldi, A. (2001). Functions of music in everyday life: An exploratory study using the experience sampling method. Musicae Scientiae, 5(1): 9-32.

Small, C. (1998). Musicking: The meanings of performing and listening. Hanover: University Press of New England.

Soley, G., \& Spelke, E. S. (2016). Shared cultural knowledge: Effects of music on young children's social preferences. Cognition 148: 106-116.

Stokes, M. (Ed.). (1994). Ethnicity, identity, and music: The musical construction of place. Oxford: Berg.

Stefano, G. B., Zhu, W., Cadet, P., Salamon, E., \& Mantione, K. J. (2004). Music alters constitutively expressed opiate and cytokine processes in listeners. Medical Science Monitor 10(6): MS18-27.

Stevens, C., \& Byron, T. (2016). Universals in music processing. In S. Hallam, I. Cross, \& M. Thaut (Eds.), Oxford Handbook of Music Psychology (pp. 19-31). Oxford: Oxford University Press.

Stupacher, J., Hove, M. J., Novembre, G., Schutz-Bosbach, S., \& Keller, P. E. (2013). Musical groove modulates motor cortex excitability: A TMS investigation. Brain and Cognition 82(2): 127-36.

Syal, S., \& Finlay, B. L. (2011). Thinking outside the cortex: Social motivation in the evolution and development of language. Developmental Science 14(2), 417-430.

Tamir, D. I., \& Mitchell, J. P. (2012). Disclosing information about the self is intrinsically rewarding. Proceedings of the National Academy of Sciences USA 109(21): 8038-43.

Tarr, B. (2017). Social bonding through dance and "Musiking." In N. L. Enfield \& P. Kockelman (Eds.), Distributed agency (pp. 151-158). Oxford University Press.

Tarr, B., Launay, J., \& Dunbar, R. I. M. (2014). Music and social bonding: "Self-other" merging and neurohormonal mechanisms. Frontiers in Psychology 5: article 1096. https://doi.org/10.3389/fpsyg.2014.01096

Tarr, B., Launay, J., Benson, C., \& Dunbar, R. I. M. (2017). Naltrexone blocks endorphins released when dancing in synchrony. Adaptive Human Behavior and Physiology 3(3): 241-54.

Tarr, B., Launay, J., Cohen, E., \& Dunbar, R. I. M. (2015). Synchrony and exertion during dance independently raise pain threshold and encourage social bonding. Biology Letters 11: 20150767. http://doi.org/http://dx.doi.org/10.1098/rsbl.2015.0767

Tarr, B., Launay, J., \& Dunbar, R. I. M. (2016). Silent disco: Dancing in synchrony leads to elevated pain thresholds and social closeness. Evolution and Human Behavior 37(5): 343-49.

Tarr, B., Slater, M., \& Cohen, E. (2018). Synchrony and social connection in immersive Virtual Reality. Scientific Reports 8: article 3693. http://doi.org/10.1038/s41598-018-21765-4 
Tchalova, K., \& Macdonald, G. (2020) Opioid receptor blockade inhibits self-disclosure during a closenessbuilding social interaction. Psychoneuroendocrinology 113:104559.

Terhardt, E. (1984). The concept of musical consonance: A link between music and psychoacoustics. Music Perception 1(3): 276-95.

Thornton, S. (1995). Club cultures: Music, media, and subcultural capital. Wesleyan University Press.

Thorpe, W. H. (1972). Duetting and antiphonal song in birds: Its extent and significance. Behaviour. Supplement 18: 1-197.

Tinbergen, N. (1963). On aims and methods of ethology. Zeitschrift Für Tierpsychologie, 20: 410-433.

Tishkoff, S. A., Reed, F. A., Ranciaro, A., Voight, B. F., Babbitt, C. C., Silverman, J. S., ... Deloukas, P. (2007). Convergent adaptation of human lactase persistence in Africa and Europe. Nature Genetics 39(1): 31-40.

Titze, I.R. (1989). Physiologic and acoustic differences between male and female voices. Journal of the Acoustical Society of America 85(4): 1699-1707.

Tolbert, E. (1990). Women cry with words: Symbolization of affect in the Karelian lament. Yearbook for Traditional Music 22: 80-105.

Tomasello, M., \& Vaish, A. (2013). Origins of human cooperation and morality. Annual Review of Psychology, 64(1): 231-255.

Tomlinson, G. (2018). Culture and the course of human evolution. University of Chicago Press.

Trainor, L. J. (2018). The origins of music: Auditory scene analysis, evolution, and culture in music creation. In H. Honing (Ed.), The origins of musicality (pp. 81-112). Cambridge, MA: MIT press.

Trainor, L. J., Austin, C. M., \& Desjardins, R. N. (2000). Is infant-directed speech prosody a result of the vocal expression of emotion? Psychological Science, 11(3), 188-195.

Trainor, L. J., Clark, E. D., Huntley, A., \& Adams, B. A. (1997). The acoustic basis of preferences for infantdirected singing. Infant Behavior and Development 20(3): 383-96.

Traulsen, A., \& Nowak, M. A. (2006). Evolution of cooperation by multilevel selection. Proceedings of the National Academy of Sciences USA 103(29): 10952-55.

Trehub, S. E. (2016). Infant musicality. In S. Hallam, I. Cross, \& M. Thaut (Eds.), The Oxford handbook of music psychology, 2nd ed. (pp. 387-397). Oxford: Oxford University Press.

Trehub, S. E., Becker, J., \& Morley, I. (2018). Cross-cultural perspectives on music and musicality. In H. Honing (Ed.), The origins of musicality (pp. 129-148). Cambridge, MA: MIT Press.

Trehub, S. E., \& Nakata, T. (2001). Emotion and music in infancy. Musicae Scientiae 5(1 Supplement): 3761.

Trehub, S. S. E., Unyk, A. A., Kamenetsky, S., Hill, D., Trainor, L. J. D., Henderson, J. L., \& Saraza, M. (1997). Mothers' and fathers' singing to infants. Developmental Psychology 33(3): 500-7.

Trehub, S.E., Unyk, A.M., \& Trainor, L.J. (1993) Adults identify infant-directed music across cultures. Infant Behavior and Development 16: 193-211.

Turchin, P., Currie, T. E., Whitehouse, H., François, P., Feeney, K., Mullins, D., ... Spencer, C. (2018). Quantitative historical analysis uncovers a single dimension of complexity that structures global variation in human social organization. Proceedings of the National Academy of Sciences USA 115(2): E144-51.

Turino, T. (2008). Music as social life: The politics of participation. Chicago: University of Chicago Press.

Valdesolo, P., \& Desteno, D. (2011). Synchrony and the social tuning of compassion. Emotion 11(2): 262-6.

Vanden Bosch der Nederlanden, C. M., Joanisse, M. F., \& Grahn, J. A. (2020). Music as a scaffold for listening to speech: Better neural phase-locking to song than speech. NeuroImage, 214, 116767. https://doi.org/10.1016/j.neuroimage.2020.116767

Vlismas, W., Malloch, S., \& Burnham, D. (2013). The effects of music and movement on mother-infant interactions. Early Child Development and Care, 183(11): 1669-88. 
Wallin, N. L., Merker, B., \& Brown, S. (Eds.). (2000). The origins of music. Cambridge: MIT Press.Walum, H., Waldman, I.D., \& Young, L.J. (2016). Statistical and methodological considerations for the interpretation of intranasal oxytocin studies. Biological Psychiatry. 79(3):251-7.

Wan, C. Y., Demaine, K., Zipse, L., Norton, A., \& Schlaug, G. (2010). From music making to speaking: Engaging the mirror neuron system in autism. Brain Research Bulletin 82(3-4): 161-68.

Wanker, R., Sugama, Y., \& Prinage, S. (2005). Vocal labelling of family members in spectacled parrotlets, Forpus conspicillatus. Animal Behaviour 70: 111-18.

Watson, A. \& Keating, D. (1999). Architecture and sound: an acoustic analysis of megalithic monuments in prehistoric Britain. Antiquity 73, 325-36.

Weinstein, D., Launay, J., Pearce, E., Dunbar, R. I. M., \& Stewart, L. (2016). Group music performance causes elevated pain thresholds and social bonding in small and large groups of singers. Evolution and Human Behavior 37(2): 152-58.

Welch, S.P., \& Eads, M. (1999). Synergistic interactions of endogenous opioids and cannabinoid systems. Brain Res. 848:183-90.

Whitehouse, H. (2004). Modes of religiosity: A cognitive theory of religious transmission. AltaMira Press.

Whitehouse, H. (2018). Dying for the group: Towards a general theory of extreme self-sacrifice. Behavioral and Brain Sciences 41: e192. http://doi.org/10.1017/S0140525X18000249

Whitehouse, H., François, P., Savage, P. E., Currie, T. E., Feeney, K. C., Cioni, E., ... Turchin, P. (2019). Complex societies precede moralizing gods throughout world history. Nature 568: 226-29.

Wickler, W. (1980). Vocal Duetting and the pair bond: 1. Coyness and partner commitment: A hypothesis. Zeitschrift für Tierpsychologie 52: 201-209.

Wiggins, G. A., Tyack, P., Scharff, C., \& Rohrmeier, M. (2018). The evolutionary roots of creativity: Mechanisms and motivations. In H. Honing (Ed.), The origins of musicality (pp. 286-308). Cambridge, MA: MIT Press.

Williams, G. C. (1966). Adaptation and natural selection: A critique of some current evolutionary thought. Princeton: Princeton University Press.

Wilson, D. S., \& Wilson, E. O. (2007). Rethinking the theoretical foundation of sociobiology. The Quarterly Review of Biology 82(4): 327-348.

Wiltermuth, S. S., \& Heath, C. (2009). Synchrony and cooperation. Psychological Science 20(1): 1-5.

Winkler, I., Háden, G. P., Ladinig, O., Sziller, I., \& Honing, H. (2009). Newborn infants detect the beat in music. Proceedings of the National Academy of Sciences USA 106(7): 2468-71.

Wood et al.(In prep.). The Global Jukebox: An interactive database of the expressive arts and culture.

Wrangham, R. (2009). Catching fire: How cooking made us human. New York: Basic Books.

Zak, P., Kurzban, R., \& Matzner, W. T. (2005). Oxytocin is associated with human trustworthiness. Hormones and Behavior 48(5): 522-27.

Zak, P., Stanton, A. A., \& Ahmadi, S. (2007). Oxytocin increases generosity in humans. PLOS ONE 2(11): e1128. http://doi.org/10.1371/journal.pone.0001128

Zaki, J., \& Mitchell, J. P. (2013). Intuitive prosociality. Current Directions in Psychological Science 22(6): 466-470.

Zatorre, R. J. (2018). Why do we love music? Cerebrum. http://www.dana.org/Cerebrum/2018/Why_Do_We_Love_Music/

Zatorre, R. J., \& Salimpoor, V. N. (2013). From perception to pleasure: Music and its neural substrates. Proceedings of the National Academy of Sciences USA 110(Supplement 2): 10430-37.

Zentner, M., \& Eerola, T. (2010). Rhythmic engagement with music in infancy. Proceedings of the National Academy of Sciences USA 107(13): 5768-73. 